\title{
Calcium in the Backstage of Malaria Parasite Biology
}

\author{
Lucas Silva de Oliveira ${ }^{1,2+}$, Marcos Rodrigo Alborghetti ${ }^{1,3+}$, Renata Garcia Carneiro ${ }^{1}$, \\ Izabela Marques Dourado Bastos ${ }^{4}$, Rogerio Amino ${ }^{5}$, Philippe Grellier ${ }^{2}$ \\ and Sébastien Charneau ${ }^{1 *}$

\begin{abstract}
${ }^{1}$ Laboratory of Biochemistry and Protein Chemistry, Department of Cell Biology, Institute of Biology, University of Brasilia, d'Histoire Naturelle, CNRS, Équipe Parasites et Protistes Libres, Paris, France, ${ }^{3}$ Brazilian Biosciences National Laboratory, Brazilian Center for Research in Energy and Materials, Campinas, Brazil, ${ }^{4}$ Laboratory of Host-Pathogen Interaction, Department of Cell Biology, Institute of Biology, University of Brasilia, Brasilia, Brazil, ${ }^{5}$ Unité Infection et Immunité Paludéennes, Institut Pasteur, Paris, France
\end{abstract} \\ Brasilia, Brazil, 2 UMR 7245 MCAM, Molécules de Communication et Adaptation des Micro-organismes, Muséum National
}

OPEN ACCESS

Edited by: Nobuko Yoshida, Federal University of São Paulo, Brazil

Reviewed by: Celia R. S. Garcia, University of São Paulo, Brazil Paul R. Gilson,

Burnet Institute, Australia Sanjay A. Desai, National Institutes of Health (NIH), United States

*Correspondence: Sébastien Charneau charneau@unb.br

${ }^{+}$These authors have contributed equally to this work

Specialty section: This article was submitted to Parasite and Host, a section of the journal Frontiers in Cellular and Infection Microbiology

Received: 12 May 2021 Accepted: 14 July 2021 Published: 28 July 2021

Citation: de Oliveira LS, Alborghetti MR, Carneiro RG, Bastos IMD, Amino R, Grellier $P$ and Charneau $S$ (2021)

Calcium in the Backstage of Malaria Parasite Biology. Front. Cell. Infect. Microbiol. 11:708834. doi: 10.3389/fcimb.2021.708834
The calcium ion $\left(\mathrm{Ca}^{2+}\right)$ is a ubiquitous second messenger involved in key biological processes in prokaryotes and eukaryotes. In Plasmodium species, $\mathrm{Ca}^{2+}$ signaling plays a central role in the parasite life cycle. It has been associated with parasite development, fertilization, locomotion, and host cell infection. Despite the lack of a canonical inositol1,4,5-triphosphate receptor gene in the Plasmodium genome, pharmacological evidence indicates that inositol-1,4,5-triphosphate triggers $\mathrm{Ca}^{2+}$ mobilization from the endoplasmic reticulum. Other structures such as acidocalcisomes, food vacuole and mitochondria are proposed to act as supplementary intracellular $\mathrm{Ca}^{2+}$ reservoirs. Several $\mathrm{Ca}^{2+}$-binding proteins (CaBPs) trigger downstream signaling. Other proteins with no EF-hand motifs, but apparently involved with CaBPs, are depicted as playing an important role in the erythrocyte invasion and egress. It is also proposed that a cross-talk among kinases, which are not members of the family of $\mathrm{Ca}^{2+}$-dependent protein kinases, such as protein kinases G, A and B, play additional roles mediated indirectly by $\mathrm{Ca}^{2+}$ regulation. This statement may be extended for proteins directly related to invasion or egress, such as SUB1, ERC, IMC1I, IMC1g, GAP45 and EBA175. In this review, we update our understanding of aspects of $\mathrm{Ca}^{2+}$-mediated signaling correlated to the developmental stages of the malaria parasite life cycle.

Keywords: $\mathrm{Ca}^{2+}$ signaling, Plasmodium, intracellular messenger, homeostasis, invasion, egress

\section{INTRODUCTION}

A plethora of cell types employ the calcium ion $\left(\mathrm{Ca}^{2+}\right)$, mobilized from extracellular and/or intracellular environments, to coordinate different $\mathrm{Ca}^{2+}$-dependent processes. The control of intracellular $\mathrm{Ca}^{2+}$ signals is dynamic. Overall, fluctuations in $\mathrm{Ca}^{2+}$ concentrations are modulated by an influx and/or efflux promoted by membrane channels, such as store-operated calcium channels (SOCEs), plasma membrane $\mathrm{Ca}^{2+}$-ATPase (PMCA) and sarco(endo)plasmic reticulum $\mathrm{Ca}^{2+}$-ATPase (SERCA) pumps. Generally, this orchestration in the $\mathrm{Ca}^{2+}$ concentration follows a signaling pathway that obeys the order: stimuli, G-protein coupled receptor, phospholipase C (PLC) 
activation, mobilization of phosphatidylinositol 4,5-biphosphate (PI(4,5)P2), production of inositol 1,4,5-phosphate (IP3), IP3 recognition by IP3-sensitive receptor channels (IP3Rs) in the endoplasmic reticulum (ER) and downstream $\mathrm{Ca}^{2+}$ cascade (Berridge et al., 2003; Clapham, 2007).

In the group of apicomplexan parasites, the protozoan parasites Toxoplasma gondii and Plasmodium spp. are the most well-established study models. In T. gondii, $\mathrm{Ca}^{2+}$ signaling is involved in specific parasite processes: motility, conoid extrusion, attachment, invasion and egress from the host cell (BorgesPereira et al., 2015; Hortua-Triana et al., 2018). Similarly, $\mathrm{Ca}^{2+}$ homeostasis and signaling have been extensively studied in Plasmodium species. Malaria is still the most life-threatening vector-borne disease globally, with an estimated 409,000 deaths and 229 million cases reported in 2019 (Global Malaria Programme: WHO Global, 2020). The increase and dissemination of antimalarial resistance (Cowman et al., 2016; Phillips et al., 2017; Global Malaria Programme: WHO Global, 2020), together with the augmentation of malaria cases since 2015, point to an urgent need for the discovery of new antimalarial drugs. The Plasmodium life cycle is strongly regulated by fluctuations in $\mathrm{Ca}^{2+}$ cellular levels, with deficiency causing impairment in parasite growth and invasion rate (Wasserman et al., 1982). This ion also acts as a messenger regulating critical Plasmodium biological processes. As such, proteins involved in $\mathrm{Ca}^{2+}$ homeostasis and signaling are strong candidates as new antimalarial targets (Gazarini et al., 2007; Vidadala et al., 2014; Mossaad et al., 2015; Bansal et al., 2016; Fang et al., 2017; Iyer et al., 2018). In this review, we present an overview of the mechanisms related to the $\mathrm{Ca}^{2+}$ homeostasis in Plasmodium species and an update of the main downstream $\mathrm{Ca}^{2+}$ signaling pathways and effectors involved in the parasite motility, invasion, development, and egress.

\section{$\mathrm{CA}^{2+}$ HOMEOSTASIS IN MALARIA PARASITES}

$\mathrm{Ca}^{2+}$ signaling is widely conserved in Eukaryotes, with reliance on this ion as a secondary messenger to switch on or off diverse biological process. Given their evolutionary distance from other Eukaryotes, malaria parasites represent a challenging task for the study of $\mathrm{Ca}^{2+}$-mediated mechanisms, with $\mathrm{Ca}^{2+}$ uptake by this microorganism presenting several peculiar features. Since Plasmodium asexual developmental stages are predominantly intracellular in red blood cells (RBCs), $\mathrm{Ca}^{2+}$ has to cross several barriers to reach the parasite, which include the red blood cell membrane (RBCM) and parasitophorous vacuole membrane (PVM) (Kirk, 2001; Kirk, 2004; Kirk and Lehane, 2014).

$\mathrm{Ca}^{2+}$ fluctuations in Plasmodium species are very complex and demand the support of intracellular $\mathrm{Ca}^{2+}$ storage. For example, gametocytes or schizont fractions from Plasmodium chabaudi infected RBCs (iRBCs) present 10-20 times more $\mathrm{Ca}^{2+}$ than uninfected RBCs. Moreover, it has been observed that this ion concentrates in parasite storage compartments (Tanabe et al., 1982). This pattern of $\mathrm{Ca}^{2+}$ concentration was also observed in
Plasmodium falciparum (Adovelande et al., 1993). To overcome these barriers and promote the observed intracellular $\mathrm{Ca}^{2+}$ increase, malaria parasites facilitate RBCM permeability, causing increased $\mathrm{Ca}^{2+}$ influx and decreased $\mathrm{Ca}^{2+}$ efflux (Tanabe et al., 1982; Desai et al., 1996). A nonselective cation conductance at RBCM, induced by $P$. falciparum growth, has been proposed as a mechanism involved in $\mathrm{Ca}^{2+}$ permeability (Brand et al., 2003; Duranton et al., 2003). Furthermore, $\mathrm{Na}^{+}$ associated to $\mathrm{Ca}^{2+}$ influx is also involved in intracellular parasite growth by this mechanism, potentially involving an ethylisopropyl-amiloride (EIPA)-sensitive channel (Brand et al., 2003).

In addition to the RBCM, PVM is another barrier to $\mathrm{Ca}^{2+}$ reaching the Plasmodium parasite. Using a cell-attached path clamp method, a 140-pS channel that is permeable to $\mathrm{Ca}^{2+}$, other ions and nutrients was identified and proposed to mediate this transport through the PVM (Desai et al., 1993). Despite such advances, mechanisms involving $\mathrm{Ca}^{2+}$ transport into malaria parasites remain poorly understood, with considerable attention now given to this area with regard to potential therapeutic intervention. Blocking the Plasmodium translocon for exported proteins machinery (PTEX)-mediated protein export across the $\mathrm{PV}$ and out into the RBC cytosol by conditional knockdown approach, significantly reduced $\mathrm{Ca}^{2+}$ permeability in iRBCs (Kushwaha et al., 2018), revealing that exported parasite proteins are potentially involved in $\mathrm{Ca}^{2+}$ uptake and transport.

Determination of the concentration of intracellular $\mathrm{Ca}^{2+}$ in apicomplexan parasites is still controversial, primarily because of the technical limitations due to inhibitors, ionophores and fluorometric measurement assay sensitivities. It is widely accepted that the intracellular concentration of $\mathrm{Ca}^{2+}$ is around 0.09-0.1 $\mu \mathrm{M}$ in physiological conditions, similar to those found in other Eukaryotes (Alleva and Kirk, 2001; Moreno et al., 2011; Lourido and Moreno, 2015). Nonetheless, an increase of up to a hundred-fold in $\mathrm{Ca}^{2+}$ concentrations was noted in the late stage of the intraerythrocytic cycle forms, ranging from 1-10 $\mu \mathrm{M}$ (Glushakova et al., 2013). Also, a high $\mathrm{Ca}^{2+}$ concentration (40 $\mu \mathrm{M})$ was reported in the parasitophorous vacuole (PV) required for proper parasite development (Gazarini et al., 2003). More recently, by using the $\mathrm{Ca}^{2+}$ sensor yellow cameleon (YC)-Nano, dynamic measurement of intracellular $\mathrm{Ca}^{2+}$ in different life stages of $P$. falciparum shows significant fluctuations throughout the parasite development: ring $(\sim 370 \mathrm{nM})$, trophozoite $(\sim 30 \mathrm{nM})$, schizont $(\sim 310 \mathrm{nM})$, merozoite $(\sim 950 \mathrm{nM})$, and gametocyte (stage III, $130 \mathrm{nM}$, stage IV-V, $\sim 520 \mathrm{nM}$ ) stages (Pandey et al., 2016).

Actors modulating such $\mathrm{Ca}^{2+}$ fluctuations have now begun to be identified, although it is still a subject under debate. For example, cytoplasmic $\mathrm{Ca}^{2+}$ increase may be related to potassium $\left(\mathrm{K}^{+}\right)$availability, especially when parasites are faced with an abrupt change from high to low $\mathrm{K}^{+}$concentration. Exposition of $P$. falciparum merozoites to an ionic environment with a low $\mathrm{K}^{+}$ concentration (which is the environment usually found by parasites after egress from RBCs) increases the levels of cytosolic $\mathrm{Ca}^{2+}$ (Singh et al., 2010). This leads to the production of cyclic-adenosine monophosphate (cAMP) by PfAC $\beta$ 
(adenylyl-cyclase $\beta$ ) upon $\mathrm{HCO}_{3}^{-}$(bicarbonate ions) stimulation, followed by activation of protein kinase A (PKA) and microneme secretion (Dawn et al., 2014; Kumar et al., 2017). However, exactly how $\mathrm{K}^{+}$acts on signaling for merozoite maturation and invasion is controversial, in contrast to intracellular cationic remodeling in iRBC (Pillai et al., 2013).

In addition, it was also demonstrated that a putative and conserved protein member from the Epac (exchange protein directly activated by cAMP, PF3D7_1417400) pathway in $P$. falciparum is potentially involved in the rise of cytosolic $\mathrm{Ca}^{2+}$ levels, facilitating P. falciparum merozoite invasion by triggering microneme secretion (Dawn et al., 2014). Nonetheless, this pathway is apparently not required for parasite growth and egress (Patel et al., 2019). Moreover, key elements in this $\mathrm{Ca}^{2+}$ mobilization were shown to involve the serpentine GPCR-like receptor PfSR25, a monovalent cation sensor coupled to PLC in triggering the cytoplasmic $\mathrm{Ca}^{2+}$ increase. Data also support the involvement of PfSR25 in parasite stress survival (Moraes et al., 2017).

Host molecules can also modulate parasite $\mathrm{Ca}^{2+}$ levels. For example, melatonin, which appears as a critical signal controlling synchronous maturation of Plasmodium in vivo, triggers an increase in $\mathrm{Ca}^{2+}$ cytoplasmic concentration through $\mathrm{Ca}^{2+}$ release from intracellular stores by an IP3-dependent pathway activation (Gazarini et al., 2003; Beraldo et al., 2005; Beraldo et al., 2007; Alves et al., 2011; Pecenin et al., 2018). Under melatonin stimulation, $\mathrm{Ca}^{2+}$ mobilization is affected by the melatonin receptor antagonist luzindole, the PLC inhibitor U73122 (Hotta et al., 2000) and IP3 receptor blockers (2-APB, 2-aminoethyl diphenylborinate derivatives) (Beraldo et al., 2007; Pecenin et al., 2018). Together, these data support a complex $\mathrm{Ca}^{2+}$-signalling network in high demand for intraerythrocytic parasite development (Figure 1).

\section{$\mathrm{CA}^{2+}$ STORAGE ORGANELLES}

\section{Endoplasmic Reticulum (ER)}

The ER is the central organelle for $\mathrm{Ca}^{2+}$ storage, with a specific pathway to control calcium influx and efflux in the cell of apicomplexan parasites (Moreno et al., 2011; Lourido and

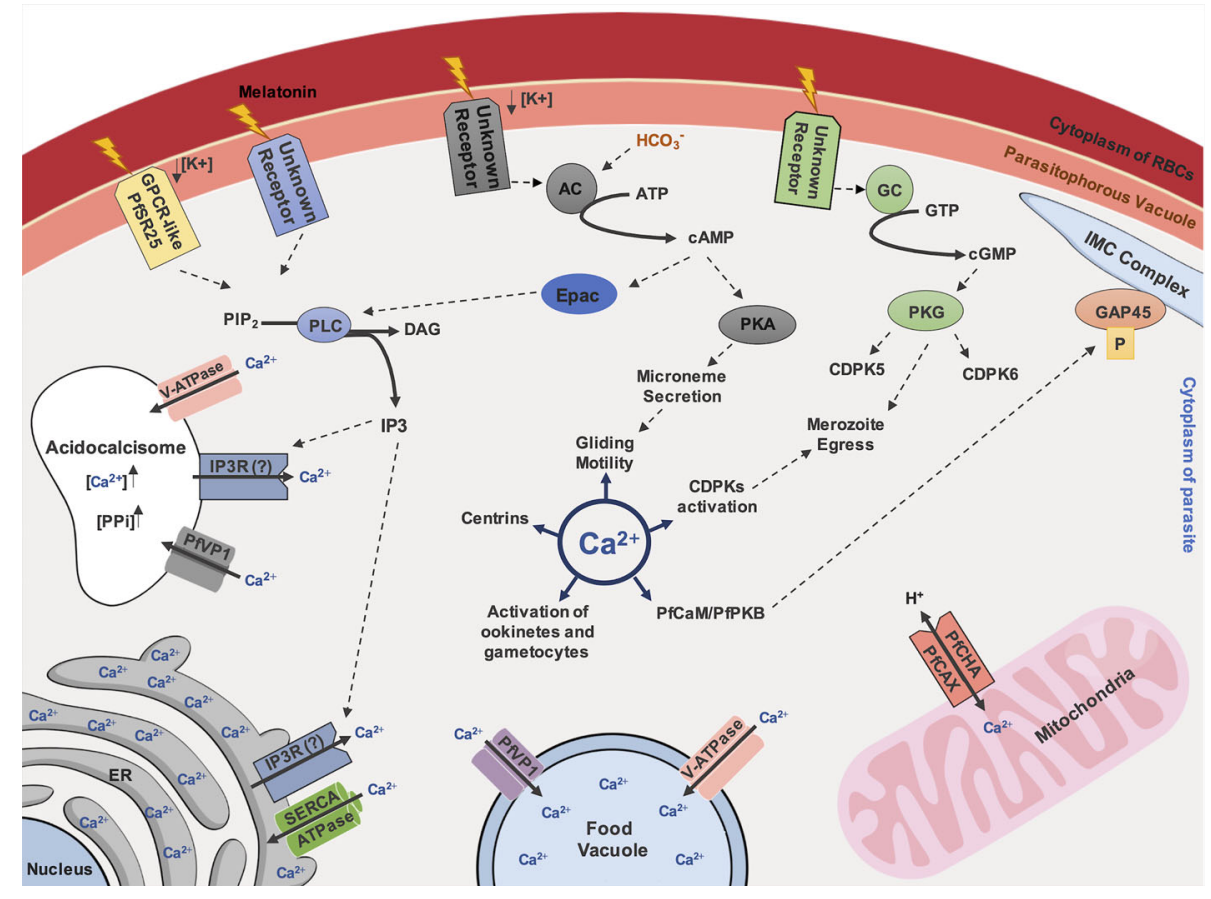

FIGURE 1 | $\mathrm{Ca}^{2+}$-dependent signaling pathway in Plasmodium species. $\mathrm{Ca}^{2+}$ inside the cytoplasm of parasite controls important processes for parasite survival, such as gliding motility, mediated by activation of PfCaM/PfPKB complex and following phosphorylation of the IMC member protein, GAP45. Additionally, centrins, CDPKs activation, activation of ookinetes and gametocytes are described as $\mathrm{Ca}^{2+}$-regulated. A GPCR-like protein, named as PfSR25, has been described as potential regulator in $\mathrm{Ca}^{2+}$ homeostasis in malaria parasites, depending on availability of potassium $\left(\mathrm{K}^{+}\right)$and mediated by IP3 signaling. Melatonin was also described as a trigger for IP3 dependent pathways. Endoplasmic Reticulum (ER) is reported as the major storage of $\mathrm{Ca}^{2+}$ and the uptake of this ion possibly depends on SERCA-type $\mathrm{Ca}^{2+}$-ATPases. $\mathrm{Ca}^{2+}$ discharge depends on receptors activated by IP3, nonetheless, an IP3R remains to be discovered in Plasmodium species. The

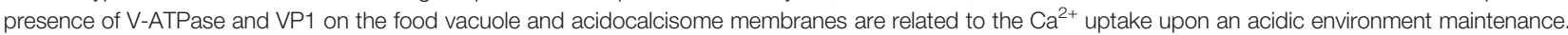
Acidocalcisome could also have an IP3R that allows exit of $\mathrm{Ca}^{2+}$. Calcium can also enter in mitochondria through Ca ${ }^{2+} / \mathrm{H}^{+}$antiporter called PfCHA/PfCAX. Activation of PKA and PKG, by cAMP and cGMP, respectively, generated by adenylyl-cyclase (AC) and guanylyl-cyclase (GC), respectively, could also participate in Ca ${ }^{2+}$ homeostasis, however the membrane receptors that stimulate theses pathways remains to be elucidated. Still, $\mathrm{upon}_{\mathrm{HCO}}{ }^{-}$activation, $\mathrm{AC}_{\mathrm{Can}}$ also stimulate Epac activation by CAMP, triggering IP3 signaling through PLC activation. Additionally, a cross-talk among kinases are also proposed to be associated to the merozoite egress mediated by proteolytic cascade events. 
Moreno, 2015). Both P. falciparum and T. gondii have $\mathrm{Ca}^{2+}$ pumps in the ER membrane, known as SERCA-type $\mathrm{Ca}^{2+}$ ATPases, that provide $\mathrm{Ca}^{2+}$ transport activity (Eckstein-Ludwig et al., 2003; Nagamune et al., 2007; Nagamune et al., 2008). PfATP6 is the only SERCA-type $\mathrm{Ca}^{2+}$-ATPase found in the $P$. falciparum genome (Gardner et al., 2002). Due to structural similarities to a SERCA inhibitor, known as thapsigargin (Thg), the antimalarial drug, artemisinin, was thought to act against PfATP6, occasionally inhibiting $\mathrm{Ca}^{2+}$ mobilization into ER. Initial evidence for this hypothesis were observed in Xenopus oocystes expressing different $P$. falciparum transporters, including PfATP6 (Eckstein-Ludwig et al., 2003). However, molecular docking and experimental validation assays showed that the interaction between P. falciparum SERCA (PfSERCA) and dihydroartemisinin (dART) was $\sim 2.3$-fold weaker than those observed between human SERCA and dART, indicating that dART do not inhibit PfSERCA pump activity, refuting the initial conclusion (Pandey et al., 2016).

Generally, $\mathrm{Ca}^{2+}$ mobilization from ER storage requires IP3 activation. The production of this molecular signal is provided by PLC (Singh and Chitnis, 2012; Brochet and Billker, 2016). Although IP3-mediated $\mathrm{Ca}^{2+}$ release from intracellular stores have been widely reported (Lovett et al., 2002; Alves et al., 2011; Glushakova et al., 2013; Pecenin et al., 2018; Borges-Pereira et al., 2020), no genetic information is known about the presence of IP3R in apicomplexan (Lourido and Moreno, 2015; Garcia et al., 2017). It has been widely accepted that a different IP3-dependent mechanism may exist in apicomplexan to mobilize $\mathrm{Ca}^{2+}$ from intracellular stores (Moreno et al., 2011; Lourido and Moreno, 2015). This statement is based on many reports, which have shown that upstream inhibition of the IP3 pathway by using PLC inhibitor (Hotta et al., 2000; Beraldo et al., 2005; Beraldo et al., 2007), and downstream inhibition by using IP3 receptor blocker (Beraldo et al., 2007; Pecenin et al., 2018) and SERCA inhibitor (Alves et al., 2011; Glushakova et al., 2013; Pecenin et al., 2018; Borges-Pereira et al., 2020), all lead to the blockage of $\mathrm{Ca}^{2+}$ mobilization in- or outward from the cytosolic environment or IP3-sensitive stores. Since there is no clear evidence that an IP3R exists at the ER in Plasmodium species, how $\mathrm{Ca}^{2+}$ mobilization occurs into this compartment and how the ER may contribute to $\mathrm{Ca}^{2+}$ homeostasis through an IP3-sensible mechanism are still unresolved.

\section{Acidic Organelles}

Other $\mathrm{Ca}^{2+}$-storage organelles are described in Apicomplexans, such as acidocalcisomes and food vacuole (FV), which stock $\mathrm{Ca}^{2+}$ in an acidic environment (Lourido and Moreno, 2015). The acidocalcisome is a lysosomal-like compartment, rich in pyrophosphate $(\mathrm{PPi})$, polyphosphate (PolyP) complexed with $\mathrm{Ca}^{2+}$ and other cations (Moreno and Docampo, 2009; Docampo and Huang, 2016). This organelle was observed in P. falciparum by Ruiz et al. (2004) after being described in other parasites, such as Trypanosoma brucei (Vercesi et al., 1994), Trypanosoma cruzi (Docampo et al., 1995) and T. gondii (Moreno and Zhong, 1996).

Two enzymes found in the $P$. falciparum genome, described as vacuolar- $\mathrm{H}^{+}$-pyrophosphatase (VP1) and vacuolar- $\mathrm{H}^{+}$-
ATPase (V-ATPase), can use PPi and ATP, respectively, to pump protons toward the lumen of acidocalcisomes, providing acidification of the structures, supporting $\mathrm{Ca}^{2+}$-storage maintenance in these organelles (Docampo et al., 2005). VP1 and V-ATPase are also localized in the FV in Plasmodium species, suggesting this acidic compartment may also have a role in regulating $\mathrm{Ca}^{2+}$-storage (Saliba et al., 2003). The potential role of these acidic organelles in $\mathrm{Ca}^{2+}$ storage is supported by the $\mathrm{V}$-ATPase and VP1 blockage in malaria parasites by their respective inhibitors, bafilomycin $\mathrm{A}_{1}$ and amino-methylenediphosphonate (AMDP), causing an increase in cytosolic $\mathrm{Ca}^{2+}$ levels (Luo et al., 1999; Biagini et al., 2003).

While the FV in malaria parasites can store around 300-400 $\mathrm{nM}$ of $\mathrm{Ca}^{2+}$, this compartment is not considered a major intracellular $\mathrm{Ca}^{2+}$ store organelle (Biagini et al., 2003; Rohrbach et al., 2005). Despite the $\mathrm{pH}$-dependency for $\mathrm{Ca}^{2+}$ maintenance in the FV, measurement of this ion is challenging, considering the different $\mathrm{pH}$ of cellular compartments (Rohrbach et al., 2005). Moreover, the role of FV is associated with hemoglobin degradation (Moura et al., 2009; Tong et al., 2018), chloroquine (CQ) action and CQ-resistance in malaria parasites (Ehlgen et al., 2012; Tong et al., 2018). P. falciparum chloroquine resistance transporter (PfCRT), present in the food vacuole membrane $(\mathrm{FVM})$, is apparently very important to balance these processes (Ehlgen et al., 2012; Lee et al., 2018), including its participation in the release of $\mathrm{Ca}^{2+}$ from FV (Lee et al., 2018).

The involvement of $\mathrm{Ca}^{2+}$ in the functions of FV was initially suggested in $P$. chabaudi by using CQ, where the balance between concentration of intracellular $\mathrm{Ca}^{2+}$ and $\mathrm{Ca}^{2+}$ in acidic organelles were affected (Gazarini et al., 2007). This could be explained by the parasite's FV permeability to low-micromolar levels of CQ, leading to $\mathrm{Ca}^{2+}$ efflux (Ch'ng et al., 2011). Despite $\mathrm{FV}$ potentially playing a role in dynamic intracellular $\mathrm{Ca}^{2+}$ storage during asexual intraerythrocytic development (Biagini et al., 2003; Lee et al., 2018), the peculiar metabolic features of this organelle shed light on the possibilities for rational drug design against Plasmodium species. For example, a recent report showed that from the 400 Pathogen Box compounds, 10 displayed disruption of $\mathrm{FV} \mathrm{Ca}{ }^{2+}$ levels comparable to those with CQ, suggesting a compromised FV membrane integrity leading to programmed cell death (PCD) in the parasite (Tong et al., 2018).

A number of reports have discussed new perspectives on acidocalcisomes in parasites. In T. gondii, the $\mathrm{Ca}^{2+} / \mathrm{H}^{+}$-ATPase (TgA1) and a vacuolar-type $\mathrm{H}^{+}$-pyrophosphatase (TgVP1) are localized in these organelles (Luo et al., 2001; Drozdowicz et al., 2003). Gene disruption revealed that $\operatorname{TgA} 1$ is required for polyphosphate storage, intracellular $\mathrm{Ca}^{2+}$ homeostasis, microneme secretion, invasion and virulence (Luo et al., 2005). Moreover, $\mathrm{Ca}^{2+}$ uptake occurs in these structures by proton pumping activity (Rohloff et al., 2011). In Trypanosoma brucei, an IP3R was found in the acidocalcisomes, suggesting that, besides the usual pathway for $\mathrm{ER} \mathrm{Ca}^{2+}$ release, IP3 can also provide additional regulation for $\mathrm{Ca}^{2+}$ mobilization from acidocalcisomes (Huang et al., 2013). Proteomic analysis of this 
structure in T. brucei confirmed the presence of IP3R. The presence of VP1, V-ATPase and vacuolar-Ca ${ }^{2+}$-ATPase (TbPMC1) was also revealed, highlighting evidence of an acidic environment for $\mathrm{Ca}^{2+}$ maintenance (Huang et al., 2014). Given the evolutionary evidence of the acidocalcisome (Docampo et al., 2010), it should be not surprising that similar mechanisms may be found in Plasmodium species, supporting $\mathrm{Ca}^{2+}$ homeostasis in these parasites (Figure 1).

\section{Mitochondrion}

Besides the primary role of mitochondria in cellular energy metabolism, they can store $\mathrm{Ca}^{2+}$ in both human and murine malaria species (Uyemura et al., 2000). Parasite mitochondria can accumulate part of the $\mathrm{Ca}^{2+}$ released in the cytoplasm by pharmacological agents, suggesting a role in maintaining $\mathrm{Ca}^{2+}$ homeostasis (Gazarini and Garcia, 2004). Interestingly, melatonin modulates transcript levels of three genes potentially related to mitochondria fusion/fission in P. falciparum: FIS1, DYN1 and DYN2 (Scarpelli et al., 2018). Considering that melatonin has already been associated with $\mathrm{Ca}^{2+}$ mobilization (Gazarini et al., 2003; Beraldo et al., 2005; Beraldo et al., 2007; Alves et al., 2011; Pecenin et al., 2018), Plasmodium mitochondrion fusion/fission could potentially be controlled by $\mathrm{Ca}^{2+}$ signaling during the asexual life cycle.

In addition, the expression of the mitochondrial $\mathrm{Ca}^{2+} / \mathrm{H}^{+}$ antiporter gene $p f c h a$ (or $\mathrm{Ca}^{2+} / \mathrm{H}^{+}$exchanger, PfCAX) from $P$. falciparum in the Xenopus laevis oocystes has been shown to cause $\mathrm{Ca}^{2+}$ uptake after the alkalinization of the intracellular environment, suggesting that the out- or inward-directed $\mathrm{Ca}^{2+}$ proton movement is $\mathrm{pH}$-dependent (Rotmann et al., 2010). Regarding this feature in $\mathrm{Ca}^{2+}$ transport in $P$. berghei, PbCAX expression has been observed in certain sexual stages (gametocytes, zygotes and ookinetes), essential to ookinete forms and parasite transmission to the mosquito in vivo, but not essential to the erythrocytic stages of $P$. berghei. A pbcax disrupted strain revealed a stage-specific role of this transporter for Plasmodium survival (Guttery et al., 2013).

$\mathrm{Ca}^{2+}$ disturbance of the Plasmodium FV caused by CQtreatment directly affects the mitochondrial transmembrane potential (Ch'ng et al., 2011; Tong et al., 2018) and triggers a PCD-like phenotype (Tong et al., 2018), providing evidence for $\mathrm{Ca}^{2+}$-regulating a functional interplay between Plasmodium FV and mitochondria. Additional studies are required to understand the roles of the malaria parasite mitochondrion in $\mathrm{Ca}^{2+}$ fluctuation and how CQ affects mitochondrial membrane potential in a $\mathrm{Ca}^{2+}$-dependent manner in the FV (Figure 1).

\section{$\mathrm{CA}^{2+}$ BINDING PROTEINS (CaBPs)}

CaBPs are conserved among species and present a helix-loophelix structural motif, known as an EF-hand motif. This motif is generally pair-structured and exposes its calcium-binding domain where two $\mathrm{Ca}^{2+}$ ions connect to it. Analysis of the $P$. falciparum genome databank (PlasmoDB) identified 103 potential proteins with EF-hand motifs. Nonetheless, this number is undoubtedly overestimated due to the divergence of the EF-hand motif and some rifins. Without rifins, 43 proteins containing EF-hands were recorded in P. falciparum (Lourido and Moreno, 2015). Some reports have proposed that this number is even lower, with about only 30 putative CaBPs (Brochet and Billker, 2016). Three main families of CaBPs are categorized in the Apicomplexa: the calmodulin (CaM) family (including centrins or caltractrins), the calcineurin B-like (CBL) family and the $\mathrm{Ca}^{2+}$-dependent protein kinases (CDPK) family (Moreno et al., 2011; Lourido and Moreno, 2015; Brochet and Billker, 2016).

Calmodulin in P. falciparum (PfCaM) is localized diffusely in the cytoplasm during mature stages of the intraerythrocytic cycle and at the apical pole end of merozoites within the ductule of rhoptries (Scheibel et al., 1987). Furthermore, a protein kinase B (PfPKB) interacts with PfCaM, which is not a member of the CDPK family, in the schizont/merozoite stages of $P$. falciparum. $\mathrm{PfPKB}$ is regulated by $\mathrm{PfCaM}$ in a $\mathrm{Ca}^{2+}$-dependent manner when the generation of IP3 by PLC mediates $\mathrm{Ca}^{2+}$ release. Consequently, PLC is an upstream modulator of PfPKB activity, regulating $\mathrm{Ca}^{2+}$ levels inside the parasite and allowing PfCaM-PfPKB interaction (Vaid and Sharma, 2006; Vaid et al., 2008). This protein complex phosphorylates PfGAP45, an anchoring protein of the actin-myosin motor complex from the IMC (inner membrane complex) (Vaid et al., 2008).

Current understanding is limited regarding a group of four P. falciparum centrins (PfCENs 1 to 4: PF3D7_0107000, PF3D7_1446600, PF3D7_1027700 and PF3D7_1105500, respectively), that contain four EF-hand motifs. This group of proteins are involved in parasite cell division at centrosome-like structures, probably in a $\mathrm{Ca}^{2+}$-dependent manner (Mahajan et al., 2008). A recent report showed that during mitosis, $\mathrm{PbCEN}-4$ is localized at distinct perinuclear foci, suggesting an association to the putative centrosomal structure, known as the microtubule-organizing center (MTOC) in P. berghei. Moreover, cen-4 gene does not seem to be compensated by increased transcription levels of other centrins and it is dispensable for malaria proliferation (Roques et al., 2019). In contrast, largescale functional screening of $P$. berghei showed that cen-1 and cen-2 genes are essential for parasite survival (Bushell et al., 2017) (Figure 1). Other $\mathrm{CaBPs}$ and their participation in diverse cellular processes in malaria parasites will be discussed in the next sections (Figure 2).

\section{$\mathrm{CA}^{2+}$-DEPENDENT PROTEIN KINASES (CDPKs)}

Protein phosphorylation is one of the most studied posttranslational modifications in eukaryotic cellular processes. Regarding the importance of $\mathrm{Ca}^{2+} / \mathrm{CaM}$ in kinase activation, many classes of $\mathrm{Ca}^{2+} / \mathrm{CaM}$-dependent kinases (CaMKs) are known in mammals. $P$. falciparum protein kinase 2 (PfPK2) is the unique homolog of human functional CaMK that phosphorylates its substrate in a $\mathrm{Ca}^{2+}$ - and CaM-dependent manner, and it is expressed during invasion (Kato et al., 2008). 


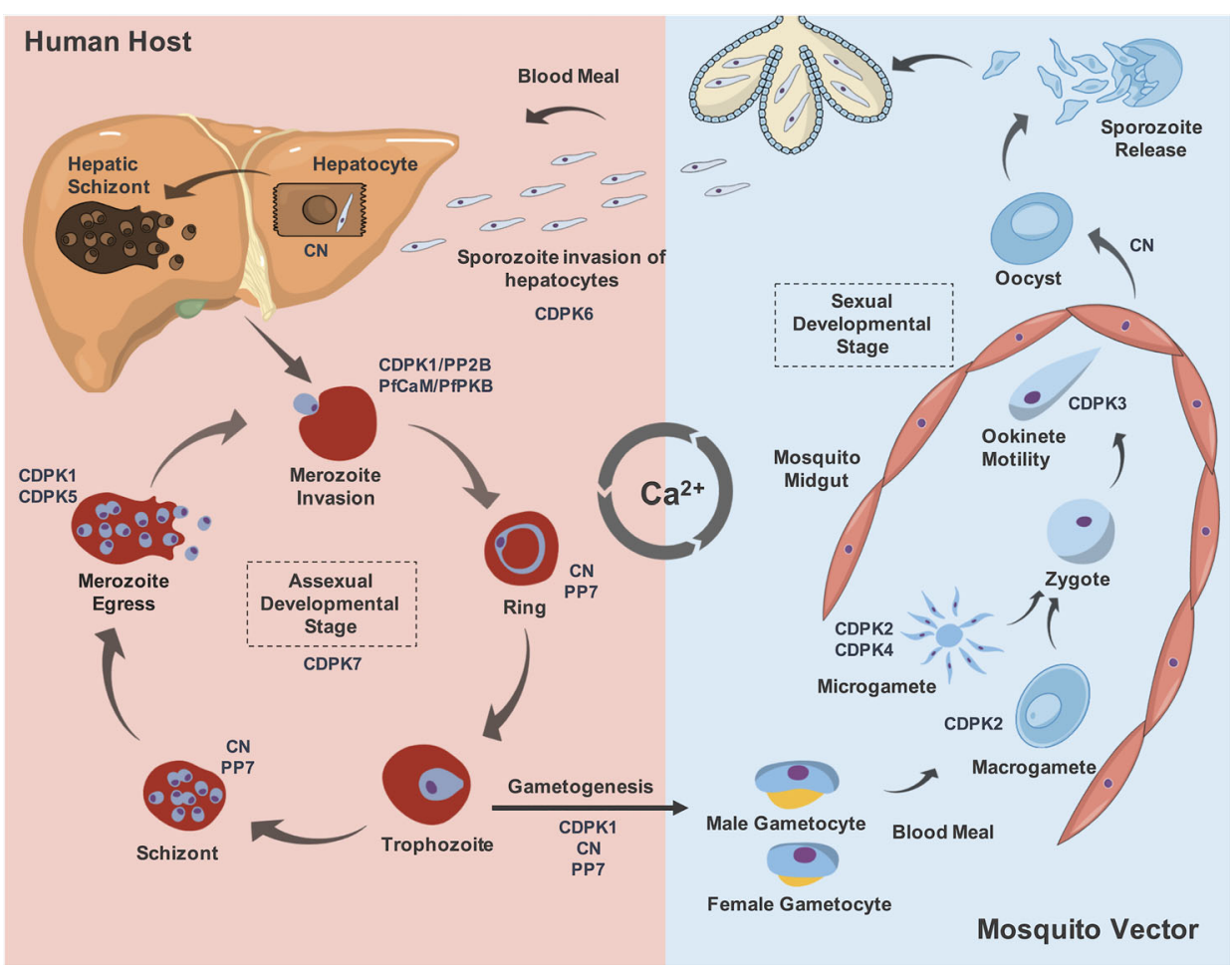

FIGURE 2 | The role of some described $\mathrm{Ca}^{2+}$-binding proteins involved in the development stage differentiation and their expression throughout Plasmodium life cycle. During the blood meal, the mosquito vector from genus Anopheles, inoculate sporozoites released from its salivary glands that will invade hepatocytes. This process is described to be CDPK6-dependent. Moreover, CN allows sporozoite-to-liver stages development inside hepatocytes. Following formation of merozoites in the liver cells, they are released in the bloodstream to continue asexual development stages, invading new RBCs. This process is mediated by CDPK1, CN and PfCaM/PfPKB complex. The role of CDPK7 to maintain the asexual developmental stages is also reported. In addition, the presence of the phosphatases CN and PP7 are implicated in the ring and schizont stages. After schizont maturation, the merozoites are released into the bloodstream to invade new RBCs, which mechanism that requires the action of CDPK1 and CDPK5. Some parasites pass through a morphological transition to form gametocytes, and this process depends on CDPK1, CN and PP7. After a blood meal of the mosquito vector, these forms maturate into male exflagellated and female gametocytes, named as microgametes and macrogametes, respectively. For this transition, CDPK2 and CDPK4 are required. These forms are fused into a zygote, which maturates to a motile ookinete. The ookinete motility is regulated by CDPK3. The ookinete exits from the lumen of mosquito midgut as an oocyst and this transition is mediated by $\mathrm{CN}$. The maturation of the oocyst will release new sporozoites which will migrate into the salivary glands of the mosquito vector. Thus, in an eventual blood meal, these new sporozoites will infect a new host and complete the parasite life cycle in order to propagate malaria disease.

However, apicomplexan parasites use a group of $\mathrm{Ca}^{2+}$ dependent protein kinases (CDPKs), which are not present in humans. Canonical CDPKs have four EF-hand $\mathrm{Ca}^{2+}$-binding domains attached to the $\mathrm{C}$-terminus of a catalytic kinase domain that shows high homology with CaMK. While CaMKs can selfinhibit through a C-terminal helix, CDPKs are regulated by their $\mathrm{Ca}^{2+}$-binding domains. In these cases, CDPKs undergo structural and conformational changes, promoting the regulation of other proteins by phosphorylation (Wernimont et al., 2010). P. falciparum possesses seven CDPKs (PfCDPK1 to PfCDPK7), with correspondent orthologs in plants, but not in animals or fungi (Kadian et al., 2017; Ghartey-Kwansah et al., 2020). It has been proposed that CDPKs could be a novel field for exploration of new antimalarial drugs (Hui et al., 2015).

For instance, transcriptomic data analysis has suggested that PfCDPK1 is primarily expressed in the late schizont stage (Bozdech et al., 2003; Le Roch et al., 2003). In agreement with this, PfCDPK1 is found in the PV and merozoite membrane throughout schizogony and merozoite egress, and performs crucial roles in the invasion process (Azevedo et al., 2013; Bansal et al., 2013). PfCDPK1 is known to phosphorylate both the myosin light chain and an IMC member, PfGAP45, in mature schizonts in vitro, when merozoites are formed (Green et al., 2008). As previously reported, PfGAP45 is also phosphorylated by PfPKB (Vaid et al., 2008), but it is proposed that this IMC member is phosphorylated on CDPK1 non-dependent phosphosites (Green et al., 2008). PfCDPK1 knockout mutants showed that this kinase is required for normal growth of $P$. falciparum during asexual proliferation, with critical involvement in gametogenesis, making its transmission to the mosquito unfeasible (Bansal et al., 2018). In contrast, CDPK1 deletion in P. berghei showed no difference for the asexual development and host cell invasion, suggesting different functions of the homologs in both species (Jebiwott et al., 2013).

PfCDPK1 mutant parasites on the bulky gatekeeper residue T145M (gatekeeper residue in the wild-type is a Thr, modified to a Met at the position 145 in the mutants) showed prominently 
reduced activity compared to wild-type parasites. This lower activity seems to be compensated by PKG, influencing the upregulation of transcription levels of CDPK5 and CDPK6 in the CDPK1 T145M mutant parasites (Bansal et al., 2016), suggesting that a $\mathrm{Ca}^{2+}$ - based signaling may modulate a very collaborative role in the CDPK family and other kinases in malaria parasites (Green et al., 2008; Brochet et al., 2014). Some reports have highlighted the importance of PfCDPK1 in the phosphorylation of members of IMC, such as GAP45 and IMC1g (Green et al., 2008; Kumar et al., 2017). PfCDPK1 knock-down mutants using the FKBP destabilization domain (DD) showed different patterns of phosphorylation in the protein-partners, revealed by iTRAQ-based phosphoproteomic analysis, including the phosphorylation pattern on S149 of PfPKA, which is a kinase also involved in $\mathrm{Ca}^{2+}$-signaling mediated by cAMP (Kumar et al., 2017). Additionally, PfCDPK1 can phosphorylate PfSERA5 (P. falciparum serine repeat antigen 5). The PfCDPK1 inhibitor, purfalcamine, blocked SERA5 phosphorylation, leading to the blockage of merozoite egress (Iyer et al., 2018). Despite this evidence on PfCDPK1 as a promising target for therapeutic intervention, a recent chemical genetics approach casts doubt on this suitability for blood stages (Green et al., 2016). Nevertheless, PfCDPK1 continues to represent a good target for a mosquito transmission-blocking strategy, as previously mentioned (Bansal et al., 2018).

In contrast to PfCDPK1, PfCDPK2 function is poorly understood in Plasmodium. In all rodent and some other malaria species, the $c d p k 2$ gene is lacking (Tewari et al., 2010). Initially thought as an essential gene in $P$. falciparum, a recent report has pointed out that in PfCDPK2 knockout mutants obtained by CRISPR-Cas9, it is dispensable in asexual proliferation in P. falciparum. Still, CDPK2 seems to play an essential role in male gametocyte exflagellation and possibly in female gametocytes, compromising parasite transmission to mosquitoes (Bansal et al., 2017). Likewise, CDPK4 has been demonstrated to play crucial roles in gametocyte exflagellation (Billker et al., 2004; Ojo et al., 2012). The bumped-kinase inhibitor 1 (BKI-1), which is more than 20-fold more selective for PfCDPK4 over PfCDPK1, inhibited the microgamete exflagellation of $P$. falciparum, but did not block asexual parasite proliferation. A strong correlation between PfCDPK4 activity inhibition and blockage of exflagellation by a series of closely related BKI analogues was observed, supporting that the exflagellation blockage was due to the inhibition of PfCDPK4 rather than other kinases. Furthermore, BKI-1 blocks P. berghei transmission to mosquitoes (Ojo et al., 2012).

The apparent role of CDPK4 in the onset of axoneme motility, DNA condensation and cytokinesis during the first 10 min of exflagellation induction has been reported (Fang et al., 2017). An increased interest in the CDPK4 as a new antimalarial target for pyrazolopyrimidine-based inhibitors has also been reported, which could result in new therapeutic strategies for malaria treatment in the near future (Vidadala et al., 2014). Regarding the sexual stages of development, CDPK3 is intimately implicated in regulating the motility of the ookinete in the mosquito vector midgut (Ishino et al., 2006; Siden-Kiamos et al., 2006). In vitro migration assays also suggested that this motility is stimulated by $\mathrm{Ca}^{2+}$ mobilization from intracellular stores (Ishino et al., 2006).

PfCDPK5 is an important regulator of parasite egress, a highly coordinated event requiring PfSERA5 (Dvorin et al., 2010; Absalon et al., 2018). The egress in CDPK5-deficient merozoites is impaired. PfCDPK5 is localized within micronemes and plays a central role in the micronene protein discharge, correlating a defect in this process to the impaired egress observed in PfCDPK5-deficient parasites. In addition, PKG has been identified as an important protein that cooperates in the egress signaling pathway together with PfCDPK5 (Absalon et al., 2018). This could explain the increased transcriptional expression levels of PKG and PfCDPK5 in the PfCDPK1 mutants as mentioned above, suggesting an integrated cross-talk among kinases in malaria parasites (Bansal et al., 2016), including their role in $\mathrm{Ca}^{2+}$ mobilization in gametocyte activation of $P$. berghei and egress of merozoites in P. falciparum (Brochet et al., 2014).

Functional studies to understand the roles of CDPK6 and CDKP7 are still lacking. PbCDPK6 has been demonstrated to play a critical role in sporozoite invasion of cells with high expression of heparan sulphate proteoglycans (HSPGs), such as hepatocytes, involving the induction of the circumsporozoite protein (CSP) cleavage upon contact with hepatocytes (Coppi et al., 2007). As previously highlighted, PfCDPK6 could be playing a compensatory role in the asexual blood stages of $P$. falciparum in the absence of a functional PfCDPK1 (Bansal et al., 2016). Still, additional studies need to be performed to address this question adequately. On the other hand, PfCDPK7 is an atypical member of the CDPK family, containing a pleckstrin homology domain adjacent to the kinase domain and two $\mathrm{Ca}^{2+}$ -binding EF-hands, present at its N-terminus. PfCDPK7 interacts with $\mathrm{PIP}_{2}$ through its pleckstrin domain, suggesting that this feature may determine its subcellular localization, possibly at ER exit sites. Moreover, knockout mutants of PfCDPK7 have also shown its importance for the growth of asexual stages of development, presenting abnormal morphology (Kumar et al., 2014). Despite this evidence on the roles of CDPK6 and CDPK7, their downstream signals, which may be implicated in other biological processes, are still largely unknown (Figure 2).

\section{$\mathrm{CA}^{2+}$-RELATED PHOSPHATASES}

Sixty-seven candidate phosphatases were identified in the $P$. falciparum genome by in silico analysis (Pandey et al., 2014). At least three serine/threonine protein phosphatases (STPP) are involved in $\mathrm{Ca}^{2+}$ signaling: STPP $2 \mathrm{~B}$ catalytic subunit A (Wilkes and Doerig, 2008; Singh et al., 2014), STPP 7 (PP7) (Kumar et al., 2004; Wilkes and Doerig, 2008; Singh et al., 2014) and a putative STPP 8 (PPP8), which is inferred as containing a $\mathrm{Ca}^{2+}$ binding site EF-hand (Yang and Arrizabalaga, 2017; Mitchell et al., 2019).

Calcineurin $(\mathrm{CN})$, also known as STPP $2 \mathrm{~B}$ or PP3, is a heterodimeric complex containing a catalytic subunit (CNA) and a regulatory subunit (CNB) (Steinbach et al., 2007). $\mathrm{CN}$ is 
conserved from yeast to humans (Yang and Arrizabalaga, 2017) and involved in several cellular processes. It has been extensively studied and reviewed (Crabtree, 2001; Wilkins and Molkentin, 2004; Liu et al., 2015; Park et al., 2019). High Ca ${ }^{2+}$ concentration induces the formation of a $\mathrm{Ca}^{2+}-\mathrm{CaM}$ complex, leading to $\mathrm{CN}$ activation, the release of its autoinhibitory domain and exposition of the active site to dephosphorylate its target (Rusnak and Mertz, 2000; Park et al., 2019).

$\mathrm{CN}$ in Plasmodium spp. is required for host cell attachment and invasion in a receptor-dependent pathway distinct from the AMA1-RON2 (apical membrane antigen-1/rhoptry neck protein 2) system but with some degree of functional overlap (Paul et al., 2015). CN knockdown demonstrated an increase of sensibility to an invasion-inhibitory antibody directed against basigin, an important receptor for $\mathrm{RBC}$ invasion, suggesting that $\mathrm{CN}$ regulates this process (Duraisingh et al., 2008; Otto et al., 2014; Paul et al., 2015). This might occur regardless of apical organelle proteins involved in invasion (Paul et al., 2015). However, CN has also been described as essential to $\mathrm{Ca}^{2+}$-dependent microneme secretion, and its activity is increased after the exposure of merozoites to a low $\mathrm{K}^{+}$environment. The mechanism involving $\mathrm{CN}$ and microneme secretion includes regulating apical actin depolymerization (Singh et al., 2014).

Stage-specific conditional degradation of $\mathrm{CN}$ in $P$. berghei further demonstrates its role in gametocyte development, fertilization and ookinete-to-oocyst and sporozoite-to-liver stage transitions (Philip and Waters, 2015). CN protein expression and/or activity regulation might provide a regulatory hub during the parasite cell cycle. The protein has been detected at the schizont, ring, sporozoite, merozoite and gametocyte stages, but not in the trophozoite stage (Wilkes and Doerig, 2008; Pandey et al., 2014). Activity inhibition by cyclosporin and FK506 resulted in increased levels of phosphorylated HSP90, phosphoglycerate kinase, actin-1, adenosine deaminase and glyceraldehyde-3-phosphate dehydrogenase. Moreover, actin-1 is potentially a direct substrate of CN in P. falciparum (Singh et al., 2014).

Similar to $\mathrm{CN}$, protein phosphatase 7 (PP7) contains EFhands and IQ (the first two amino acids of the motif: Ile and Gln) calmodulin-binding motifs but, in contrast, is monomeric. The CaM-binding motif was found to inhibit phosphatase activity in Arabidopsis PP7 (Dobson et al., 2001; Kutuzov et al., 2001; Yang and Arrizabalaga, 2017). PP7 is not detected at the trophozoite stage but at the schizont, ring, merozoite and gametocyte stages (Dobson et al., 2001; Pandey et al., 2014). These observations indicate that PfPP7 is regulated across all parasite stages and could constitute a potential target to control the parasite cell cycle. PP8 or EFPP is a putative STPP with a long N-terminal domain with EF-hand motifs and is specific to apicomplexans. Mutations were observed in their catalytic domain which put into question their phosphatase activity. Their functions have not yet been investigated (Kutuzov and Andreeva, 2008; Yang and Arrizabalaga, 2017).

Most studies involving the roles of $\mathrm{Ca}^{2+}$ signaling and phosphatases are focused on calcineurin. However, other phosphatases without $\mathrm{Ca}^{2+}$-binding motifs could be affected by
$\mathrm{Ca}^{2+}$ signaling through their protein partners possessing these motifs. According to STRING prediction and Gene Ontology analyses, amongst the 67 candidate phosphatases identified in $P$. falciparum, ten potentially interact with proteins involved in $\mathrm{Ca}^{2+}$ signaling: putative acid phosphatase (PF3D7_0918000), putative protein phosphatase 2C (PF3D7_0829100), putative 4-nitrophenylphosphatase (PF3D7_0715000), putative protein phosphatase (PF3D7_0802800), putative RNA lariat debranching enzyme (PF3D7_1340600), putative acid phosphatase (PF3D7_1403900), hypothetical protein (PF3D7_1464600), hypothetical protein (PF3D7_1469200), protein phosphatase 2C (PF3D7_0410300) and putative phosphoesterase (PF3D7_ 1206000) (Pandey et al., 2014). However, the effects of $\mathrm{Ca}^{2+}$ on the phosphatase protein-interaction network remain poorly understood in Plasmodium species. Therefore, biochemical assays and phosphatase protein partner screenings are a reasonable approach for discovery of new antimalarials (Khalife and Pierrot, 2016).

\section{OTHER EFFECTORS INVOLVED IN CA ${ }^{2+}$ SIGNALING}

P. falciparum reticulocyte binding-like protein 1 (PfRh1) performs a role in initial sensing of $\mathrm{Ca}^{2+}$ followed by signal transduction, causing erythrocyte binding antigen-175 (EBA175) release from microneme and allowing tight junction formation (Gao et al., 2013). The biochemical pathways regarding $\mathrm{Ca}^{2+}$ modulation that led to microneme secretion are largely unknown, highlighting the need for further studies in Plasmodium species. As previously mentioned, components of the motor complex involved in merozoite invasion are phosphorylated by PfCDPK1 (Green et al., 2008; Vaid et al., 2008). In P. berghei sporozoites, this complex is involved in gliding motility and host cell invasion. Living-cell imaging studies demonstrate that while cytoplasmic elevated $\mathrm{Ca}^{2+}$ levels are required for gliding, alone this is insufficient, since artificial increases using an ionophore allowed adhesin translocation to the surface but no gliding motion (Carey et al., 2014). Moreover, the P. falciparum inner membrane complex 11 (PfIMC11) has been proposed as a protein to potentially connect this motor complex to the IMC membrane. It is also involved in gliding and invasion processes in a $\mathrm{Ca}^{2+}$-dependent manner. PfIMC1l interacts directly with $\mathrm{Ca}^{2+}$ and its interaction with actin is enhanced in the presence of this ion (Kumar et al., 2019). The gliding motility used by ookinete and merozoite invasion is also supported by CDPK4, in a compensatory manner to CDPK1 (and vice versa). Both $\mathrm{Ca}^{2+}$-dependent kinases are involved in IMC stability, phosphorylating the glideosome-associated protein 40 (GAP40) and the CDPK4 substrate SOC6 (PBANKA_070770), involved in IMC biogenesis (Fang et al., 2018).

Following microneme secretion, the interaction of PfEBA-175 and the RBCs receptor glycophorin A (glyA) results in a cytoplasmic lowering of $\mathrm{Ca}^{2+}$ levels, which, in turn, stimulates the release of rhoptry proteins such as cytoadherence-linked 
asexual protein gene 3.1 (CLAG3.1/RhopH1) and P. falciparum reticulocyte binding-like protein $2 \mathrm{~b}$ (PfRh2b) (Singh et al., 2010). Rhoptry discharge in RBCs contributes to the tight-junction and PV formation, modifying the host cell environment (Boothroyd and Dubremetz, 2008; Santos and Soldati-Favre, 2011). The repression of $P$. berghei rhoptry neck protein 11 (PbRON11) in sporozoites reduced attachment and motility, leading to the impairment of the infection in the mosquito salivary gland and hepatocyte cells. This protein contains putative EF-hand domains and might act by controlling rhoptry protein secretion in a $\mathrm{Ca}^{2+}$-dependent manner (Bantuchai et al., 2019).

Merozoite egress from RBCs is triggered by elevation of cyclic guanosine monophosphate (cGMP) and PKG activation, essential for the protein discharge of secretory organelles, known to support this process (Collins et al., 2013; Alam et al., 2015). Correlation of $\mathrm{Ca}^{2+}$ with parasite egress was previously reported (Collins et al., 2013; Glushakova et al., 2013). Events documented in the final hour of the cell cycle include $\mathrm{Ca}^{2+}$ release from ER of the schizonts, activation of PfCDPK5 and, in the last 10-20 minutes of the cell cycle, vacuole swelling and red blood cell cytoskeleton destabilization by calpain, a host enzyme activated by $\mathrm{Ca}^{2+}$ (Glushakova et al., 2013). More recently, PKG was found to interact with and phosphorylate a multipass membrane protein, termed as important for $\mathrm{Ca}^{2+}$ mobilization 1 (ICM1). Conditional knockdown of ICM1 revealed an essential role in $\mathrm{Ca}^{2+}$ mobilization to initiate both Plasmodium gametogenesis and merozoite egress (Balestra et al., 2021). Additionally, guanylyl-cyclase alpha (GC $\alpha$ )null mutant parasites were unable to synthesize cGMP for PKG activation in schizonts, leading to a reduction in $\mathrm{Ca}^{2+}$ release from internal stores (Nofal et al., 2021).

Conditional gene disruption of the $P$. falciparum phosphodiesterase $\beta$ (PfPDE $\beta$ ) leads to a dramatic reduction in schizont cAMP and cGMP hydrolytic activity, resulting in elevated cAMP levels and inappropriate cAMP-induced increased phosphorylation of PKA substrates. In addition, PKA seem to assume a compensatory role with $\mathrm{PKG}$, in order to phosphorylate $P$. falciparum myosin A (PfMyoA), an important component of the so-called glideosome, a parasite complex involved in host cell invasion, in PfPDE $\beta$ mutants, bypassing the need for PKG activity by elevated cAMP levels upon $\mathrm{Ca}^{2+}$ signaling, possibly by PKA action (Flueck et al., 2019). Together, these findings point towards PfPDE $\beta$ regulating cAMP and cGMP production, followed by PKA and PKG activation. Nonetheless, the molecular dynamics of $\mathrm{Ca}^{2+}$ signaling associated with these events are still poorly understood.

A family of proteins containing multiple EF-hand motifs, named as the CREC family (calumenin, reticulocalbin 1 and 3, ERC-55, Cab-45), has been remarkably underexplored, considering that proteins from this family are widely found from protozoans to mammals (Honore and Vorum, 2000). A member of this family is found in the ER of $P$. falciparum, known as PfERC (endoplasmic reticulum-resident calcium-binding protein) (La Greca et al., 1997). This protein is a key regulator of the egress proteolytic cascade of $P$. falciparum merozoites. The use of SERCA inhibitor cyclopiazonic acid (CPA) and an ionophore, ionomycin, did not change the amounts of cytosolic $\mathrm{Ca}^{2+}$ in knockdown parasites bearing a glucosamineinducible ribozyme gene (PfERC-glmS) from ER or neutral $\mathrm{Ca}^{2+}$ storages, suggesting that the availability of $\mathrm{Ca}^{2+}$ from different sources does not change upon knockdown of PfERC. Moreover, PfERC is required for the complete maturation of the aspartic protease plasmepsin $\mathrm{X}(\mathrm{PMX})$ in a $\mathrm{Ca}^{2+}$-dependent manner, which is required to cleave the subtilisin-like protease (SUB1) (Fierro et al., 2020).

Additional evidence for $\mathrm{Ca}^{2+}$ importance for SUB1 discharge and proteolytic cascade events have been reported. Chelation of intracellular $\mathrm{Ca}^{2+}$ in $P$. falciparum schizonts blocks the SUB1 discharge from merozoite exonemes into $\mathrm{PV}$, resulting in a decrease of SERA5 proteolytic cleavage and harming PVM rupture and merozoite egress (Agarwal et al., 2013). Mature SUB1 discharge into PV results in the proteolytic cleavage of protein family members involved in merozoite egress and RBC invasion, such as SERA5 and MSP1 (merozoite surface protein 1) (Nasamu et al., 2017; Pino et al., 2017). Additionally to SERA5, SERA6 has been associated to the parasite egress from RBCs upon SUB1 catalytic processing into the PV (Ruecker et al., 2012). In the absence of SERA6, the rupture of RBCM does not occur, suggesting that SERA6 could be associated to an additional proteolytic cascade event related to the $\beta$-spectrin cleavage of host cell cytoskeleton (Thomas et al., 2018). Moreover, autocatalytic maturation of SERA6 needs a PVlocated protein cofactor, named merozoite surface antigen 180, which is also a SUB1 substrate. This multi-step proteolytic process is required for dismantling the host $\mathrm{RBC}$ cytoskeleton facilitating the parasite egress (Tan et al., 2021). Therefore, it remains to be further described how $\mathrm{Ca}^{2+}$ may modulate actors in these proteolytic cascade events.

$\mathrm{Ca}^{2+}$ signaling has also been shown to be involved in preerythrocytic cycle stages. After hepatocyte invasion, elongated sporozoites transform into a spherical form (exo-erythrocytic form, EEF) in a temperature-dependent process (Shortt and Garnham, 1948; Meis et al., 1983; Kaiser et al., 2003). It has been proposed that the $\mathrm{Ca}^{2+}$ signal regulates this morphological transition, with intracellular $\mathrm{Ca}^{2+}$ increased at the center of a bulbous structure in $P$. berghei, reinforcing that $\mathrm{Ca}^{2+}$ plays central roles in diverse life-cycle stages (Doi et al., 2011). Sporozoite salivary gland proteome analyses revealed several components that could be involved in the $\mathrm{Ca}^{2+}$ signaling pathway at this stage, such as G-protein-coupled receptors, adenylyl and guanylyl cyclases and a carbonic anhydrase. Host proteins are also involved in $\mathrm{EEF}$ transformations and $\mathrm{Ca}^{2+}$ signaling. Protein kinase $\mathrm{C}-$ mediated NF- $\mathrm{\kappa B}$ activation induces expression of CXCR4 (C-X-C chemokine receptor type 4) in hepatocytes and intracellular $\mathrm{Ca}^{2+}$ elevation, essential to EEF development (Bando et al., 2019). The interplay between host and parasite proteins, however, remains highly elusive.

\section{CONCLUDING REMARKS}

Plasmodium species contain distinctive features when compared to other eukaryotes. Such characteristics define its phylum or 
genus, in which attachment to the host cell, motility, invasion and egress are essential for survival and dissemination. Since $\mathrm{Ca}^{2+}$ signaling regulates important and specific Plasmodium cellular processes such as microneme secretion, attachment, gliding motility, invasion and egress, actors involved in these pathways, which are regulated by this ion, could be considered potential drug targets. Striking progress to achieve a broader understanding of $\mathrm{Ca}^{2+}$ signaling in Plasmodium has been made, including the potential involvement of host compounds in $\mathrm{Ca}^{2+}$ uptake, such as $\mathrm{K}^{+}, \mathrm{Na}^{+}$, ionic strength and melatonin (Brand et al., 2003; Gazarini et al., 2003; Singh et al., 2010; Pillai et al., 2013; Pecenin et al., 2018).

However, several gaps in understanding remain in these organisms, covering mechanisms involved in increased $\mathrm{Ca}^{2+}$ uptaking by iRBCs, together with transport through PVM and the parasite cellular membrane. Moreover, IP3R or alternative functional protein identification in Plasmodium would be an important breakthrough to explore $\mathrm{Ca}^{2+}$ mobilization and storage, as well as backstage actors which support those processes as promising therapeutic targets. Actually, a plethora of Plasmodium proteins with standard and unusual $\mathrm{Ca}^{2+}$ binding motifs, which are known or suspected to be involved in $\mathrm{Ca}^{2+}$ signaling, could be explored to this end. This also includes proteins without $\mathrm{Ca}^{2+}$-binding motifs acting as indirect effectors.

The association of classical techniques employed to study permeability, protein channels and pumps, together with more recent high-throughput approaches is a promise to fulfill these gaps. Mass spectrometry-based proteomics (Garcia et al., 2018;

\section{REFERENCES}

Absalon, S., Blomqvist, K., Rudlaff, R. M., DeLano, T. J., Pollastri, M. P., and Dvorin, J. D. (2018). Calcium-Dependent Protein Kinase 5 Is Required for Release of Egress-Specific Organelles in Plasmodium Falciparum. MBio 9, 1-16. doi: 10.1128/mBio.00130-18

Adovelande, J., Bastide, B., Deleze, J., and Schrevel, J. (1993). Cytosolic Free Calcium in Plasmodium Falciparum-Infected Erythrocytes and the Effect of Verapamil: A Cytofluorometric Study. Exp. Parasitol. 76, 247-258. doi: 10.1006/expr.1993.1030

Agarwal, S., Singh, M. K., Garg, S., Chitnis, C. E., and Singh, S. (2013). Ca2+Mediated Exocytosis of Subtilisin-Like Protease 1: A Key Step in Egress of Plasmodium Falciparum Merozoites. Cell. Microbiol. 15, 910-921. doi: $10.1111 / \mathrm{cmi} .12086$

Alam, M. M., Solyakov, L., Bottrill, A. R., Flueck, C., Siddiqui, F. A., Singh, S., et al. (2015). Phosphoproteomics Reveals Malaria Parasite Protein Kinase G as a Signalling Hub Regulating Egress and Invasion. Nat. Commun. 6, 7285. doi: $10.1038 /$ ncomms 8285

Alleva, L. M., and Kirk, K. (2001). Calcium Regulation in the Intraerythrocytic Malaria Parasite Plasmodium Falciparum. Mol. Biochem. Parasitol. 117, 121128. doi: 10.1016/S0166-6851(01)00338-3

Alves, E., Bartlett, P. J., Garcia, C. R. S., and Thomas, A. P. (2011). Melatonin and $\mathrm{IP}(3)$-Induced $\mathrm{Ca}(2+)$ Release From Intracellular Stores in the Malaria Parasite Plasmodium Falciparum Within Infected Red Blood Cells. J. Biol. Chem. 286, 5905-5912. doi: 10.1074/jbc.M110.188474

Azevedo, M. F., Sanders, P. R., Krejany, E., Nie, C. Q., Fu, P., Bach, L. A., et al. (2013). Inhibition of Plasmodium Falciparum CDPK1 by Conditional Expression of Its J-Domain Demonstrates a Key Role in Schizont Development. Biochem. J. 452, 433-441. doi: 10.1042/BJ20130124

Balestra, A. C., Koussis, K., Klages, N., Howell, S. A., Flynn, H. R., Bantscheff, M., et al. (2021). Ca2+ Signals Critical for Egress and Gametogenesis in Malaria Parasites Depend on a Multipass Membrane Protein That Interacts With PKG. Sci. Adv. 7 (13), 1-17. doi: 10.1126/sciadv.abe5396
Blomqvist et al., 2020; Garcia et al., 2021), including novel proteomic approaches to understand in vivo protein-partners, such as BioID and APEX-2 proximity-labelling techniques (Rhee et al., 2013; Kehrer et al., 2016; Boucher et al., 2018; Birnbaum et al., 2020), metabolomics (Beri et al., 2019) and new $\mathrm{Ca}^{2+}$ ratiometric techniques coupled to imaging reporters (Brochet et al., 2014; Carey et al., 2014; Pandey et al., 2016; Absalon et al., 2018; Borges-Pereira et al., 2020) are examples of such technologies required for improved understanding of the role of $\mathrm{Ca}^{2+}$ in the backstage of malaria parasite biology and drug screening assay design.

\section{AUTHOR CONTRIBUTIONS}

All authors contributed to the article and approved the submitted version.

\section{ACKNOWLEDGMENTS}

We would like to thank the CAPES/COFECUB programme [923/18], CAPES-PROEX, INCT-MCTI/CNPq/FAPs [16/ 2014], CNPq Universal [430610/2016-5], and FAPDF [Demanda Espontânea 193.001.723/2017]. We also thank Pr. Concepta McManus Pimentel and Pr. Robert Neil Gerard Miller at University of Brasilia for orthographic correction.

Bando, H., Pradipta, A., Iwanaga, S., Okamoto, T., Okuzaki, D., Tanaka, S., et al. (2019). CXCR4 Regulates Plasmodium Development in Mouse and Human Hepatocytes. J. Exp. Med. 216, 1733-1748. doi: 10.1084/jem.20182227

Bansal, A., Molina-Cruz, A., Brzostowski, J., Liu, P., Luo, Y., Gunalan, K., et al. (2018). PfCDPK1 Is Critical for Malaria Parasite Gametogenesis and Mosquito Infection. Proc. Natl. Acad. Sci. U. S. A. 115, 774-779. doi: 10.1073/pnas.1715443115

Bansal, A., Molina-Cruz, A., Brzostowski, J., Mu, J., and Miller, L. H. (2017). Plasmodium Falciparum Calcium-Dependent Protein Kinase 2 Is Critical for Male Gametocyte Exflagellation But Not Essential for Asexual Proliferation. MBio 8, 1-17. doi: 10.1128/mBio.01656-17

Bansal, A., Ojo, K. K., Mu, J., Maly, D. J., van Voorhis, W. C., and Miller, L. H. (2016). Reduced Activity of Mutant Calcium-Dependent Protein Kinase 1 Is Compensated in Plasmodium Falciparum Through the Action of Protein Kinase G. MBio 7, 1-12. doi: 10.1128/mBio.02011-16

Bansal, A., Singh, S., More, K. R., Hans, D., Nangalia, K., Yogavel, M., et al. (2013). Characterization of Plasmodium Falciparum Calcium-Dependent Protein Kinase 1 (PFCDPK1) and Its Role in Microneme Secretion During Erythrocyte Invasion. J. Biol. Chem. 288, 1590-1602. doi: 10.1074/ jbc.M112.411934

Bantuchai, S., Nozaki, M., Thongkukiatkul, A., Lorsuwannarat, N., Tachibana, M., Baba, M., et al. (2019). Rhoptry Neck Protein 11 has Crucial Roles During Malaria Parasite Sporozoite Invasion of Salivary Glands and Hepatocytes. Int. J. Parasitol 49, (9):725-735. doi: 10.1016/j.ijpara.2019.05.001

Beraldo, F. H., Almeida, F. M., Da Silva, A. M., and Garcia, C. R. S. (2005). Cyclic AMP and Calcium Interplay as Second Messengers in Melatonin-Dependent Regulation of Plasmodium Falciparum Cell Cycle. J. Cell Biol. 170, 551-557. doi: $10.1083 /$ jcb.200505117

Beraldo, F. H., Mikoshiba, K., and Garcia, C. R. S. (2007). Human Malarial Parasite, Plasmodium Falciparum, Displays Capacitative Calcium Entry: 2Aminoethyl Diphenylborinate Blocks the Signal Transduction Pathway of Melatonin Action on the P. Falciparum Cell Cycle. J. Pineal Res. 43, 360364. doi: 10.1111/j.1600-079X.2007.00486.x 
Beri, D., Ramdani, G., Balan, B., Gadara, D., Poojary, M., Momeux, L., et al. (2019). Insights Into Physiological Roles of Unique Metabolites Released From Plasmodium-Infected RBCs and Their Potential as Clinical Biomarkers for Malaria. Sci. Rep. 9, 1-11. doi: 10.1038/s41598-018-37816-9

Berridge, M. J., Bootman, M. D., and Roderick, H. L. (2003). Calcium Signalling: Dynamics, Homeostasis and Remodelling. Nat. Rev. Mol. Cell Biol. 4, 517-529. doi: $10.1038 / \mathrm{nrm} 1155$

Biagini, G. A., Bray, P. G., Spiller, D. G., White, M. R. H., and Ward, S. A. (2003). The Digestive Food Vacuole of the Malaria Parasite Is a Dynamic Intracellular Ca2+ Store. J. Biol. Chem. 278, 27910-27915. doi: 10.1074/jbc.M304193200

Billker, O., Dechamps, S., Tewari, R., Wenig, G., Franke-Fayard, B., and Brinkmann, V. (2004). Calcium and a Calcium-Dependent Protein Kinase Regulate Gamete Formation and Mosquito Transmission in a Malaria Parasite. Cell 117, 503-514. doi: 10.1016/S0092-8674(04)00449-0

Birnbaum, J., Scharf, S., Schmidt, S., Jonscher, E., Maria Hoeijmakers, W. A., Flemming, S., et al. (2020). A Kelch13-Defined Endocytosis Pathway Mediates Artemisinin Resistance in Malaria Parasites. Science (80-.) 367, 51-59. doi: $10.1126 /$ science.aax4735

Blomqvist, K., Helmel, M., Wang, C., Absalon, S., Labunska, T., Rudlaff, R. M., et al. (2020). Influence of Plasmodium Falciparum Calcium-Dependent Protein Kinase 5 (PfCDPK5) on the Late Schizont Stage Phosphoproteome. mSphere 5, 1-10. doi: 10.1128/mSphere.00921-19

Boothroyd, J. C., and Dubremetz, J. F. (2008). Kiss and Spit: The Dual Roles of Toxoplasma Rhoptries. Nat. Rev. Microbiol. 6, 79-88. doi: 10.1038/ nrmicro1800

Borges-Pereira, L., Budu, A., McKnight, C. A., Moore, C. A., Vella, S. A., Triana, M. A. H., et al. (2015). Calcium Signaling Throughout the Toxoplasma Gondii Lytic Cycle a Study Using Genetically Encoded Calcium Indicators. J. Biol. Chem. 290, 26914-26926. doi: 10.1074/jbc.M115.652511

Borges-Pereira, L., Thomas, S. J., dos Anjos e Silva, A. L., Bartlett, P. J., Thomas, A. P., and Garcia, C. R. S. (2020). The Genetic Ca2+ Sensor GCaMP3 Reveals Multiple Ca2+ Stores Differentially Coupled to Ca2+ Entry in the Human Malaria Parasite Plasmodium Falciparum. J. Biol. Chem. 295, 14998-15012. doi: 10.1074/jbc.RA120.014906

Boucher, M. J., Ghosh, S., Zhang, L., Lal, A., Jang, S. W., Ju, A., et al. (2018). Integrative Proteomics and Bioinformatic Prediction Enable a HighConfidence Apicoplast Proteome in Malaria Parasites. PloS Biol. 16, 1-29. doi: 10.1371/journal.pbio.2005895

Bozdech, Z., Llinás, M., Pulliam, B. L., Wong, E. D., Zhu, J., and DeRisi, J. L. (2003). The Transcriptome of the Intraerythrocytic Developmental Cycle of Plasmodium Falciparum. PloS Biol. 1, 85-100. doi: 10.1371/journal.pbio.0000005

Brand, V. B., Sandu, C. D., Duranton, C., Lang, K. S., Huber, S. M., and Lang, F. (2003). Growth on the Cation Permeability of the Human Host Erythrocyte. Cell. Physiol. Biochem. 13, 347-356. doi: 10.1159/000075122

Brochet, M., and Billker, O. (2016). Calcium Signalling in Malaria Parasites. Mol. Microbiol. 100, 397-408. doi: 10.1111/mmi.13324

Brochet, M., Collins, M. O., Smith, T. K., Thompson, E., Sebastian, S., Volkmann, K., et al. (2014). Phosphoinositide Metabolism Links cGMP-Dependent Protein Kinase G to Essential Ca2+ Signals at Key Decision Points in the Life Cycle of Malaria Parasites. PloS Biol. 12 (13), 1-15. doi: 10.1371/journal.pbio.1001806

Bushell, E., Gomes, A. R., Sanderson, T., Anar, B., Girling, G., Herd, C., et al. (2017). Functional Profiling of a Plasmodium Genome Reveals an Abundance of Essential Genes. Cell 170, 260-272.e8. doi: 10.1016/j.cell.2017.06.030

Carey, A. F., Singer, M., Bargieri, D., Thiberge, S., Frischknecht, F., Ménard, R., et al. (2014). Calcium Dynamics of Plasmodium Berghei Sporozoite Motility. Cell. Microbiol. 16, 768-783. doi: 10.1111/cmi.12289

Ch'ng, J. H., Liew, K., Goh, A. S. P., Sidhartha, E., and Tan, K. S. W. (2011). DrugInduced Permeabilization of Parasite's Digestive Vacuole Is a Key Trigger of Programmed Cell Death in Plasmodium Falciparum. Cell Death Dis. 2, 1-11. doi: $10.1038 /$ cddis.2011.97

Clapham, D. E. (2007). Calcium Signaling. Cell 131, 1047-1058. doi: 10.1016/ j.cell.2007.11.028

Collins, C. R., Hackett, F., Strath, M., Penzo, M., Withers-Martinez, C., Baker, D. A., et al. (2013). Malaria Parasite cGMP-Dependent Protein Kinase Regulates Blood Stage Merozoite Secretory Organelle Discharge and Egress. PloS Pathog. 9 (5), 1-13. doi: 10.1371/journal.ppat.1003344

Coppi, A., Tewari, R., Bishop, J. R., Bennett, B. L., Lawrence, R., Esko, J. D., et al. (2007). Heparan Sulfate Proteoglycans Provide a Signal to Plasmodium
Sporozoites to Stop Migrating and Productively Invade Host Cells. Cell Host Microbe 2, 316-327. doi: 10.1016/j.chom.2007.10.002

Cowman, A. F., Healer, J., Marapana, D., and Marsh, K. (2016). Malaria: Biology and Disease. Cell 167, 610-624. doi: 10.1016/j.cell.2016.07.055

Crabtree, G. R. (2001). Calcium, Calcineurin, and the Control of Transcription. J. Biol. Chem. 276 (4), 2313-2316. doi: 10.1074/jbc.R000024200

Dawn, A., Singh, S., More, K. R., Siddiqui, F. A., Pachikara, N., Ramdani, G., et al. (2014). The Central Role of cAMP in Regulating Plasmodium Falciparum Merozoite Invasion of Human Erythrocytes. PloS Pathog. 10 (12), 1-14. doi: 10.1371/journal.ppat.1004520

Desai, S. A., Krogstad, D. J., and McCleskey, E. W. (1993). A Nutrient-Permeable Channel on the Intraerythrocytic Malaria Parasite. Nature 362, 643-646. doi: $10.1038 / 362643 \mathrm{a} 0$

Desai, S. A., McCleskey, E. W., Schlesinger, P. H., and Krogstad, D. J. (1996). A Novel Pathway for Ca2+ Entry Into Plasmodium Falciparum-Infected Blood Cells. Am. J. Trop. Med. Hyg. 54, 464-470. doi: 10.4269/ajtmh.1996.54.464

Dobson, S., Bracchi, V., Chakrabarti, D., and Barik, S. (2001). Characterization of a Novel Serine/Threonine Protein Phosphatase (PfPPJ) From the Malaria Parasite, Plasmodium Falciparum. Mol. Biochem. Parasitol. 115, 29-39. doi: 10.1016/S0166-6851(01)00260-2

Docampo, R., de Souza, W., Miranda, K., Rohloff, P., and Moreno, S. N. J. (2005). Acidocalcisomes - Conserved From Bacteria to Man. Nat. Rev. Microbiol. 3, 251-261. doi: 10.1038/nrmicro1097

Docampo, R., and Huang, G. (2016). Acidocalcisomes of Eukaryotes. Curr. Opin. Cell Biol. 41, 66-72. doi: 10.1016/j.ceb.2016.04.007

Docampo, R., Scott, D. A., Vercesi, A. E., and Moreno, S. N. J. (1995). Intracellular Ca2+ Storage in Acidocalcisomes of Trypanosoma Cruzi. Biochem. J. 310, 1005-1012. doi: 10.1042/bj3101005

Docampo, R., Ulrich, P., and Moreno, S. N. J. (2010). Evolution of Acidocalcisomes and Their Role in Polyphosphate Storage and Osmoregulation in Eukaryotic Microbes. Philos. Trans. R. Soc B Biol. Sci. 365, 775-784. doi: 10.1098/rstb.2009.0179

Doi, Y., Shinzawa, N., Fukumoto, S., Okano, H., and Kanuka, H. (2011). Calcium Signal Regulates Temperature-Dependent Transformation of Sporozoites in Malaria Parasite Development. Exp. Parasitol 128 (2), 176-180. doi: 10.1016/ j.exppara.2011.02.011

Drozdowicz, Y. M., Shaw, M., Nishi, M., Striepen, B., Liwinski, H. A., Roos, D. S., et al. (2003). Isolation and Characterization of TgVP1, a Type I Vacuolar H+Translocating Pyrophosphatase From Toxoplasma Gondii: The Dynamics of Its Subcellular Localization and the Cellular Effects of a Diphosphonate Inhibitor. J. Biol. Chem. 278, 1075-1085. doi: 10.1074/jbc.M209436200

Duraisingh, M. T., DeSimone, T., Jennings, C., Refour, P., and Wu, C. (2008). Erythrocyte Invasion by Plasmodium Fakipamm: Multiple Ligand-Receptor Interactions and Phenotypic Switching. Subcell. Biochem. 46-57. doi: 10.1007/ 978-0-387-78267-6_3

Duranton, C., Huber, S. M., Karl, S., Brand, V. B., Sandu, C. D., and Lang, F. (2003). Cellular Physiology Biochemistry and Biochemistr Y Electrophysiological Properties of the Plasmo- Dium Falciparum-Induced Cation Conductance of Human Erythrocytes. Cell. Physiol. Biochem. 49, 189-198. doi: 10.1159/000072421

Dvorin, J. D., Martyn, D. C., Patel, S. D., Grimley, J. S., Collins, R., Hopp, C. S., et al. (2010). A Plant-Like Kinase in Plasmodium Falciparum Regulates Parasite Egress From Erythrocytes. Science (80-.) 328, 910-912. doi: 10.1126/ science.1188191.A

Eckstein-Ludwig, U., Webb, R. J., Van Goethem, I. D. A., East, J. M., Lee, A. G., Kimura, M., et al. (2003). Artemisinins Target the SERCA of Plasmodium Falciparum. Nature 424, 957-961. doi: 10.1038/nature01813

Ehlgen, F., Pham, J. S., de Koning-Ward, T., Cowman, A. F., and Ralph, S. A. (2012). Investigation of the Plasmodium Falciparum Food Vacuole Through Inducible Expression of the Chloroquine Resistance Transporter (PfCRT). PloS One 7 (6), 1-12. doi: 10.1371/journal.pone.0038781

Fang, H., Gomes, A. R., Klages, N., Pino, P., Maco, B., Walker, E. M., et al. (2018). Epistasis Studies Reveal Redundancy Among Calcium-Dependent Protein Kinases in Motility and Invasion of Malaria Parasites. Nat. Commun. 9 (4248), 1-14. doi: 10.1038/s41467-018-06733-w

Fang, H., Klages, N., Baechler, B., Hillner, E., Yu, L., Pardo, M., et al. (2017). Multiple Short Windows of Calcium-Dependent Protein Kinase 4 Activity Coordinate Distinct Cell Cycle Events During Plasmodium Gametogenesis. Elife 6, 1-23. doi: 10.7554/eLife.26524 
Fierro, M. A., Asady, B., Brooks, C. F., Cobb, D. W., Villegas, A., Moreno, S. N. J., et al. (2020). An Endoplasmic Reticulum CREC Family Protein Regulates the Egress Proteolytic Cascade in Malaria Parasites. MBio 11, 1-21. doi: 10.1128/ mBio.03078-19

Flueck, C., Drought, L. G., Jones, A., Patel, A., Perrin, A. J., Walker, E. M., et al. (2019). Phosphodiesterase Beta Is the Master Regulator of cAMP Signalling During Malaria Parasite Invasion. PloS Biol. 17, 1-32. doi: 10.1371/ journal.pbio.3000154

Gao, X., Gunalan, K., Yap, S. S. L., and Preiser, P. R. (2013). Triggers of Key Calcium Signals During Erythrocyte Invasion by Plasmodium Falciparum. Nat. Commun. 4 (2862), 1-11. doi: 10.1038/ncomms3862

Garcia, C. R. S., Alves, E., Pereira, P. H. S., Bartlett, P. J., Thomas, A. P., Mikoshiba, K., et al. (2017). InsP3 Signaling in Apicomplexan Parasites. Curr. Top. Med. Chem. 17, 2158-2165. doi: 10.2174/1568026617666170130121042

Garcia, C. H. S., Depoix, D., Carvalho, P. C., Bastos, I. M. D., Ricart, C. A. O., de Sousa, M. V., et al. (2021). Comparative Proteomic Analysis of Kinesin-8B Deficient Plasmodium Berghei During Gametogenesis. J. Proteomics 236, 104118. doi: 10.1016/j.jprot.2021.104118

Garcia, C. H. S., Depoix, D., Queiroz, R. M. L., Souza, J. M. F., Fontes, W., de Sousa, M. V., et al. (2018). Dynamic Molecular Events Associated to Plasmodium Berghei Gametogenesis Through Proteomic Approach. J. Proteomics 180, 88-98. doi: 10.1016/j.jprot.2017.11.009

Gardner, M. J., Hall, N., Fung, E., White, O., Berriman, M., Hyman, R. W., et al. (2002). Genome Sequence of the Human Malaria Parasite Plasmodium Falciparum. Nature 419, 498-511. doi: 10.1038/nature01097

Gazarini, M. L., and Garcia, C. R. S. (2004). The Malaria Parasite Mitochondrion Senses Cytosolic Ca 2+ Fluctuations. Biochem. Biophys. Res. Commun. 321, 138-144. doi: 10.1016/j.bbrc.2004.06.141

Gazarini, M. L., Sigolo, C. A. O., Markus, R. P., Thomas, A. P., and Garcia, C. R. S. (2007). Antimalarial Drugs Disrupt Ion Homeostasis in Malarial Parasites. Mem. Inst. Oswaldo Cruz 102, 329-334. doi: 10.1590/S0074-02762007000300012

Gazarini, M. L., Thomas, A. P., Pozzan, T., and Garcia, C. R. S. (2003). Calcium Signaling in a Low Calcium Environment: How the Intracellular Malaria Parasite Solves the Problem. J. Cell Biol. 161, 103-110. doi: 10.1083/jcb.200212130

Ghartey-Kwansah, G., Yin, Q., Li, Z., Gumpper, K., Sun, Y., Yang, R., et al. (2020). Calcium-Dependent Protein Kinases in Malaria Parasite Development and Infection. Cell Transplant. 29, 1-12. doi: 10.1177/0963689719884888

Global Malaria Programme: WHO Global (2020). World Malaria Report. Available at: https://www.who.int/publications/i/item/9789240015791.

Glushakova, S., Lizunov, V., Blank, P. S., Melikov, K., Humphrey, G., and Zimmerberg, J. (2013). Cytoplasmic Free Ca 2 + Is Essential for Multiple Steps in Malaria Parasite Egress From Infected Erythrocytes. Malar. J. 12, 1-12. doi: 10.1186/1475-2875-12-41

Green, J. L., Moon, R. W., Whalley, D., Bowyer, P. W., Wallace, C., Rochani, A., et al. (2016). Imidazopyridazine Inhibitors of Plasmodium Falciparum Calcium-Dependent Protein Kinase 1 Also Target Cyclic GMP-Dependent Protein Kinase and Heat Shock Protein 90 to Kill the Parasite at Different Stages of Intracellular Development. Antimicrob. Agents Chemother. 60, 14641475. doi: 10.1128/AAC.01748-15

Green, J. L., Rees-Channer, R. R., Howell, S. A., Martin, S. R., Knuepfer, E., Taylor, H. M., et al. (2008). The Motor Complex of Plasmodium Falciparum: Phosphorylation by a Calcium-Dependent Protein Kinase. J. Biol. Chem. 283, 30980-30989. doi: 10.1074/jbc.M803129200

Guttery, D. S., Pittman, J. K., Frénal, K., Poulin, B., McFarlane, L. R., Slavic, K., et al. (2013). The Plasmodium Berghei $\mathrm{Ca} 2+/ \mathrm{H}+$ Exchanger, PbCAX, Is Essential for Tolerance to Environmental Ca2+ During Sexual Development. PloS Pathog. 9 (2), 1-17. doi: 10.1371/journal.ppat.1003191

Honore, B., and Vorum, H. (2000). The CREC Family, a Novel Family of Multiple EF-Hand, Low-Affinity Ca2+-Binding Proteins Localised to the Secretory Pathway of Mammalian Cells. FEBS Lett. 466, 11-18. doi: 10.1016/S00145793(99)01780-9

Hortua-Triana, M. A., Márquez-Nogueras, K. M., Vella, S. A., and Moreno, S. N. J. (2018). Calcium Signaling and the Lytic Cycle of the Apicomplexan Parasite Toxoplasma Gondii. Biochim. Biophys. Acta Mol. Cell Res. 1865, 1846-1856. doi: 10.1016/j.bbamcr.2018.08.004

Hotta, C. T., Gazarini, M. L., Beraldo, F. H., Varotti, F. P., Lopes, C., Markus, R. P., et al. (2000). Calcium-Dependent Modulation by Melatonin of the Circadian Rhythm in Malarial Parasites. Nat. Cell Biol. 2, 466-468. doi: 10.1038/35017112
Huang, G., Bartlett, P. J., Thomas, A. P., Moreno, S. N. J., and Docampo, R. (2013). Acidocalcisomes of Trypanosoma Brucei Have an Inositol 1,4,5-Trisphosphate Receptor That Is Required for Growth and Infectivity. PNAS 110 (12), 18871892. doi: 10.1371/journal.ppat.1004555

Huang, G., Ulrich, P. N., Storey, M., Johnson, D., Tischer, J., Tovar, J. A., et al. (2014). Proteomic Analysis of the Acidocalcisome, an Organelle Conserved From Bacteria to Human Cells. PloS Pathog. 10 (12), 1-17. doi: 10.1371/ journal.ppat. 1004555

Hui, R., El Bakkouri, M., and Sibley, L. D. (2015). Designing Selective Inhibitors for Calcium-Dependent Protein Kinases in Apicomplexans. Trends Pharmacol. Sci. 36, 452-460. doi: 10.1016/j.tips.2015.04.011

Ishino, T., Orito, Y., Chinzei, Y., and Yuda, M. (2006). A Calcium-Dependent Protein Kinase Regulates Plasmodium Ookinete Access to the Midgut Epithelial Cell. Mol. Microbiol. 59, 1175-1184. doi: 10.1111/j.13652958.2005.05014.x

Iyer, G. R., Singh, S., Kaur, I., Agarwal, S., Siddiqui, M. A., Bansal, A., et al. (2018). Calcium-Dependent Phosphorylation of Plasmodium Falciparum Serine Repeat Antigen 5 Triggers Merozoite Egress. J. Biol. Chem. 293, 9736-9746. doi: $10.1074 /$ jbc.RA117.001540

Jebiwott, S., Govindaswamy, K., Mbugua, A., and Bhanot, P. (2013). Plasmodium Berghei Calcium Dependent Protein Kinase 1 Is Not Required for Host Cell Invasion. PloS One 8, 1-5. doi: 10.1371/journal.pone.0079171

Kadian, K., Gupta, Y., Kempaiah, P., Gupta, N., and Rawat, M. (2017). Calcium Dependent Protein Kinases (CDPKs): Key to Malaria Eradication. Curr. Top. Med. Chem. 17, (19):1-6. doi: 10.2174/1568026617666170130112714

Kaiser, K., Camargo, N., and Kappe, S. H. I. (2003). Transformation of Sporozoites Into Early Exoerythrocytic Malaria Parasites Does Not Require Host Cells. J. Exp. Med. 197, 1045-1050. doi: 10.1084/jem.20022100

Kato, K., Sudo, A., Kobayashi, K., Tohya, Y., and Akashi, H. (2008). Characterization of Plasmodium Falciparum Protein Kinase 2. Mol. Biochem. Parasitol. 162, 87-95. doi: 10.1016/j.molbiopara.2008.07.007

Kehrer, J., Frischknecht, F., and Mair, G. R. (2016). Proteomic Analysis of the Plasmodium Berghei Gametocyte Egressome and Vesicular BioID of Osmiophilic Body Proteins Identifies Merozoite TRAP-Like Protein (MTRAP) as an Essential Factor for Parasite Transmission. Mol. Cell. Proteomics 15, 2852-2862. doi: 10.1074/mcp.m116.058263

Khalife, J., and Pierrot, C. (2016). Phosphatases are Emerging as Novel Druggable Targets in Plasmodium. Future Microbiol. 11, 603-606. doi: 10.2217/fmb2016-0029

Kirk, K. (2001). Membrane Transport in the Malaria-Infected Erythrocyte. Physiol. Rev. 81, 495-537. doi: 10.1152/physrev.2001.81.2.495

Kirk, K. (2004). Channels and Transporters as Drug Targets in the PlasmodiumInfected Erythrocyte. Acta Trop. 89, 285-298. doi: 10.1016/j.actatropica.2003.10.002

Kirk, K., and Lehane, A. M. (2014). Membrane Transport in the Malaria Parasite and its Host Erythrocyte. Biochem. J. 457, 1-18. doi: 10.1042/BJ20131007

Kumar, V., Behl, A., Kapoor, P., Nayak, B., Singh, G., Singh, A. P., et al. (2019). Inner Membrane Complex 11 Protein of Plasmodium Falciparum Links Membrane Lipids With Cytoskeletal Element 'Actin' and Its Associated Motor 'Myosin.'. Int. J. Biol. Macromol. 126 (1), 673-684. doi: 10.1016/ j.ijbiomac.2018.12.239

Kumar, S., Kumar, M., Ekka, R., Dvorin, J. D., Paul, A. S., Madugundu, A. K., et al. (2017). PfCDPK1 Mediated Signaling in Erythrocytic Stages of Plasmodium Falciparum. Nat. Commun. 8, 1-12. doi: 10.1038/s41467-017-00053-1

Kumar, R., Musiyenko, A., Oldenburg, A., Adams, B., and Barik, S. (2004). PostTranslational Generation of Constitutively Active Cores From Larger Phosphatases in the Malaria Parasite, Plasmodium Falciparum: Implications for Proteomics. BMC Mol. Biol. 5, 1-15. doi: 10.1186/1471-2199-5-6

Kumar, P., Tripathi, A., Ranjan, R., Halbert, J., Gilberger, T., Doerig, C., et al. (2014). Regulation of Plasmodium Falciparum Development by CalciumDependent Protein Kinase 7 (PfCDPK7). J. Biol. Chem. 289, 20386-20395. doi: $10.1074 /$ jbc.M114.561670

Kushwaha, A. K., Apolis, L., Ito, D., and Desai, S. A. (2018). Increased Ca2+ Uptake by Erythrocytes Infected With Malaria Parasites: Evidence for Exported Proteins and Novel Inhibitors. Cell. Microbiol. 20, 1-12. doi: $10.1111 / \mathrm{cmi} .12853$

Kutuzov, M. A., and Andreeva, A. V. (2008). Protein Ser/Thr Phosphatases of Parasitic Protozoa. Mol. Biochem. Parasitol. 161, 81-90. doi: 10.1016/ j.molbiopara.2008.06.008 
Kutuzov, M. A., Bennett, N., and Andreeva, A. V. (2001). Interaction of Plant Protein Ser/Thr Phosphatase PP7 With Calmodulin. Biochem. Biophys. Res. Commun. 289, 634-640. doi: 10.1006/bbrc.2001.6020

La Greca, N., Hibbs, A. R., Riffkin, C., Foley, M., and Tilley, L. (1997). Identification of an Endoplasmic Reticulum-Resident Calcium-Binding Protein With Multiple EFHand Motifs in Asexual Stages of Plasmodium Falciparum. Mol. Biochem. Parasitol. 89, 283-293. doi: 10.1016/S0166-6851(97)00134-5

Lee, A. H., Dhingra, S. K., Lewis, I. A., Singh, M. K., Siriwardana, A., Dalal, S., et al. (2018). Evidence for Regulation of Hemoglobin Metabolism and Intracellular Ionic Flux by the Plasmodium Falciparum Chloroquine Resistance Transporter. Sci. Rep. 8, 1-13. doi: 10.1038/s41598-018-31715-9

Le Roch, K. G., Zhou, Y., Blair, P. L., Grainger, M., Moch, J. K., Haynes, J. D., et al. (2003). Discovery of Gene Function by Expression Profiling of the Malaria Parasite Life Cycle. Science (80-.) 301, 1503-1508. doi: 10.1126/science.1087025

Liu, S., Hou, Y., Liu, W., Lu, C., Wang, W., and Sun, S. (2015). Components of the Calcium-Calcineurin Signaling Pathway in Fungal Cells and Their Potential as Antifungal Targets. Eukaryot. Cell 14 (4), 324-334. doi: 10.1128/EC.00271-14

Lourido, S., and Moreno, S. N. J. (2015). The Calcium Signaling Toolkit of the Apicomplexan Parasites Toxoplasma Gondii and Plasmodium Ssp. Cell Calcium 57, 186-193. doi: 10.1016/j.ceca.2014.12.010.The

Lovett, J. L., Marchesini, N., Moreno, S. N. J., and David Sibley, L. (2002). Toxoplasma Gondii Microneme Secretion Involves Intracellular Ca2+ Release From Inositol 1,4,5-Triphosphate (IP3)/ryanodine-Sensitive Stores. J. Biol. Chem. 277, 25870-25876. doi: 10.1074/jbc.M202553200

Luo, S., Marchesini, N., Moreno, S. N. J., and Docampo, R. (1999). A Plant-Like Vacuolar H+-Pyrophosphatase in Plasmodium Falciparum. FEBS Lett. 460, 217-220. doi: 10.1016/S0014-5793(99)01353-8

Luo, S., Ruiz, F. A., and Moreno, S. N. J. (2005). The Acidocalcisome Ca2+ -ATPaSe (TgA1) of Toxoplasma Gondii is Required for Polyphosphate Storage, Intracellular Calcium Homeostasis and Virulence. Mol. Microbiol. 55, 1034-1045. doi: 10.1111/j.1365-2958.2004.04464.x

Luo, S., Vieira, M., Graves, J., Zhong, L., and Moreno, S. N. J. (2001). A Plasma Membrane-Type Ca2+-ATPase Co-Localizes With a Vacuolar H+ -Pyrophosphatase to Acidocalcisomes of Toxoplasma Gondii. EMBO J. 20, 55-64. doi: 10.1093/emboj/20.1.55

Mahajan, B., Selvapandiyan, A., Gerald, N. J., Majam, V., Zheng, H., Wickramarachchi, T., et al. (2008). Centrins, Cell Cycle Regulation Proteins in Human Malaria Parasite Plasmodium Falciparum. J. Biol. Chem. 283, 31871-31883. doi: 10.1074/jbc.M800028200

Meis, J. F. G. M., Verhave, J. P., Jap, P. H. K., Sinden, R. E., and Meuwissen, J. H. E. T. (1983). Malaria Parasites - Discovery of the Early Liver Form. Nature 302, 424-426. doi: 10.1038/302424a0

Mitchell, A. L., Attwood, T. K., Babbitt, P. C., Blum, M., Bork, P., Bridge, A., et al. (2019). InterPro in 2019: Improving Coverage, Classification and Access to Protein Sequence Annotations. Nucleic Acids Res 47 (D1), 351-360. doi: 10.1093/nar/gky1100

Moraes, M. S., Budu, A., Singh, M. K., Borges-Pereira, L., Levano-Garcia, J., Currà, C., et al. (2017). Plasmodium Falciparum GPCR-Like Receptor SR25 Mediates Extracellular K+ Sensing Coupled to Ca2+ Signaling and Stress Survival. Sci. Rep. 7, 1-13. doi: 10.1038/s41598-017-09959-8

Moreno, S. N. J., Ayong, L., and Pace, D. A. (2011). Calcium Storage and Function in Apicomplexan Parasites. Essays Biochem. 51, 97-110. doi: 10.1042/ bse0510097.Calcium

Moreno, S. N. J., and Docampo, R. (2009). The Role of Acidocalcisomes in Parasitic Protists. J. Eukaryot. Microbiol. 56, 208-213. doi: 10.1111/j.15507408.2009.00404.x

Moreno, S. N. J., and Zhong, L. (1996). Acidocalcisomes in Toxoplasma Gondii Tachyzoites. Biochem. J. 313, 655-659. doi: 10.1042/bj3130655

Mossaad, E., Furuyama, W., Enomoto, M., Kawai, S., Mikoshiba, K., and Kawazu, S. I. (2015). Simultaneous Administration of 2-Aminoethyl Diphenylborinate and Chloroquine Reverses Chloroquine Resistance in Malaria Parasites. Antimicrob. Agents Chemother. 59, 2890-2892. doi: 10.1128/AAC.04805-14

Moura, P. A., Dame, J. B., and Fidock, D. A. (2009). Role of Plasmodium Falciparum Digestive Vacuole Plasmepsins in the Specificity and Antimalarial Mode of Action of Cysteine and Aspartic Protease Inhibitors. Antimicrob. Agents Chemother. 53, 4968-4978. doi: 10.1128/AAC.00882-09

Nagamune, K., Beatty, W. L., and Sibley, L. D. (2007). Artemisinin Induces Calcium-Dependent Protein Secretion in the Protozoan Parasite Toxoplasma Gondii. Eukaryot. Cell 6, 2147-2156. doi: 10.1128/EC.00262-07
Nagamune, K., Moreno, S. N., Chini, E. N., and Sibley, L. D. (2008). Calcium Regulation and Signaling in Apicomplexan Parasites. Mol. Mech. Parasite Invasion 47, 70-81. doi: 10.1007/978-0-387-78267-6_5

Nasamu, A. S., Glushakova, S., Russo, I., Vaupel, B., Kim, A. S., Fremont, D. H., et al. (2017). Plasmepsins IX and X are Essential and Druggable Mediators of Malaria Parasite Egress and Invasion. Science (80-.) 518, 518-522. doi: 10.1126/ science.aan 1478

Nofal, S. D., Patel, A., Blackman, M. J., Flueck, C., and Baker, D. A. (2021). Plasmodium Falciparum Guanylyl Cyclase-Alpha and the Activity of its Appended P4-ATPase Domain are Essential for cGMP Synthesis and BloodStage Egress. MBio 12, 1-19. doi: 10.1128/mBio.02694-20

Ojo, K. K., Billker, O., Van Voorhis, W. C., Ojo, K. K., Pfander, C., Mueller, N. R., et al. (2012). Transmission of Malaria to Mosquitoes Blocked by Bumped Kinase Inhibitors. J. Clin. Invest. 122, 2301-2305. doi: 10.1172/ JCI61822.powers

Otto, T. D., Rayner, J. C., Böhme, U., Pain, A., Spottiswoode, N., Sanders, M., et al. (2014). Genome Sequencing of Chimpanzee Malaria Parasites Reveals Possible Pathways of Adaptation to Human Hosts. Nat. Commun. 5 (4754), 1-9. doi: $10.1038 /$ ncomms5754

Pandey, K., Ferreira, P. E., Ishikawa, T., Nagai, T., Kaneko, O., and Yahata, K. (2016). Ca2+ Monitoring in Plasmodium Falciparum Using the Yellow Cameleon-Nano Biosensor. Sci. Rep. 6, 1-13. doi: 10.1038/srep23454

Pandey, R., Mohmmed, A., Pierrot, C., Khalife, J., Malhotra, P., and Gupta, D. (2014). Genome Wide in Silico Analysis of Plasmodium Falciparum Phosphatome. BMC Genomics 15 (1024), 1-22. doi: 10.1186/1471-2164-151024

Park, H. S., Lee, S. C., Cardenas, M. E., and Heitman, J. (2019). CalciumCalmodulin-Calcineurin Signaling: A Globally Conserved Virulence Cascade in Eukaryotic Microbial Pathogens. Cell Host Microbe 26 (4), 453-462. doi: 10.1016/j.chom.2019.08.004

Patel, A., Perrin, A. J., Flynn, H. R., Bisson, C., Withers-Martinez, C., Treeck, M., et al. (2019). Cyclic AMP Signalling Controls Key Components of Malaria Parasite Host Cell Invasion Machinery. PloS Biol 17 (5), 1-33. doi: 10.1371/ journal.pbio. 3000264

Paul, A. S., Saha, S., Engelberg, K ., Jiang, R. H. Y., Coleman, B. I., Kosber, A. L., et al. (2015). Parasite Calcineurin Regulates Host Cell Recognition and Attachment by Apicomplexans. Cell Host Microbe 18, 49-60. doi: 10.1016/ j.chom.2015.06.003

Pecenin, M. F., Borges-Pereira, L., Levano-Garcia, J., Budu, A., Alves, E., Mikoshiba, K., et al. (2018). Blocking IP3 Signal Transduction Pathways Inhibits Melatonin-Induced Ca2+ Signals and Impairs P. Falciparum Development and Proliferation in Erythrocytes. Cell Calcium 72, 81-90. doi: $10.1016 /$ j.ceca.2018.02.004

Philip, N., and Waters, A. P. (2015). Conditional Degradation of Plasmodium Calcineurin Reveals Functions in Parasite Colonization of Both Host and Vector. Cell Host Microbe 18, 122-131. doi: 10.1016/j.chom.2015.05.018

Phillips, M. A., Burrows, J. N., Manyando, C., van Huijsduijnen, R. H., Van Voorhis, W. C., and Wells, T. N. C. (2017). Malaria. Nat. Rev. Dis. Primers 3, 124. doi: 10.1016/S0140-6736(18)30324-6

Pillai, A. D., Addo, R., Sharma, P., Nguitragool, W., Srinivasan, P., and Desai, S. A. (2013). Malaria Parasites Tolerate a Broad Range of Ionic Environments and do Not Require Host Cation Remodelling. Mol. Microbiol. 88, 20-34. doi: $10.1111 / \mathrm{mmi} .12159$

Pino, P., Caldelari, R., Mukherjee, B., Vahokoski, J., Klages, N., Maco, B., et al. (2017). A Multistage Antimalarial Targets the Plasmepsins IX and X Essential for Invasion and Egress. Science (80-.) 528, 522-528. doi: 10.1126/ science.aaf 8675

Rhee, H., Zou, P., Udeshi, N. D., Martell, J. D., Mootha, V. K., Carr, S. A., et al. (2013). Proteomic Mapping of Mitochondria in Living Cells Via Spatially Restricted Enzymatic Tagging. Science 339, 1328-1331. doi: 10.1126/ science. 1230593

Rohloff, P., Miranda, K., Rodrigues, J. C. F., Fang, J., Galizzi, M., Plattner, H., et al. (2011). Calcium Uptake and Proton Transport by Acidocalcisomes of Toxoplasma Gondii. PloS One 6 (4), 1-9. doi: 10.1371/journal.pone.0018390

Rohrbach, P., Friedrich, O., Hentschel, J., Plattner, H., Fink, R. H. A., and Lanzer, M. (2005). Quantitative Calcium Measurements in Subcellular Compartments of Plasmodium Falciparum-Infected Erythrocytes. J. Biol. Chem. 280, 2796027969. doi: 10.1074/jbc.M500777200 
Roques, M., Stanway, R. R., Rea, E. I., Markus, R., Brady, D., Holder, A. A., et al. (2019). Plasmodium Centrin PbCEN-4 Localizes to the Putative MTOC and is Dispensable for Malaria Parasite Proliferation. Biol. Open 8, bio036822. doi: $10.1242 /$ bio. 036822

Rotmann, A., Sanchez, C., Guiguemde, A., Rohrbach, P., Dave, A., Bakouh, N., et al. (2010). PfCHA Is a Mitochondrial Divalent Cation/H+ Antiporter in Plasmodium Falciparum. Mol. Microbiol. 76, 1591-1606. doi: 10.1111/j.13652958.2010.07187.x

Ruecker, A., Shea, M., Hackett, F., Suarez, C., Hirst, E. M. A., Milutinovic, K., et al. (2012). Proteolytic Activation of the Essential Parasitophorous Vacuole Cysteine Protease SERA6 Accompanies Malaria Parasite Egress From Its Host Erythrocyte. J. Biol. Chem. 287, 37949-37963. doi: 10.1074/jbc.M112.400820

Ruiz, F. A., Luo, S., Moreno, S. N. J., and Docampo, R. (2004). Polyphosphate Content and Fine Structure of Acidocalcisomes of Plasmodium Falciparum. Microsc. Microanal. 10, 563-567. doi: 10.1017/S1431927604040875

Rusnak, F., and Mertz, P. (2000). Calcineurin: Form and Function. Physiol. Rev. 80, 1483-1521. doi: 10.1152/physrev.2000.80.4.1483

Saliba, K. J., Allen, R. J. W., Zissis, S., Bray, P. G., Ward, S. A., and Kirk, K. (2003). Acidification of the Malaria Parasite's Digestive Vacuole by a H+-ATPase and a H+-Pyrophosphatase. J. Biol. Chem. 278, 5605-5612. doi: 10.1074/ jbc.M208648200

Santos, J. M., and Soldati-Favre, D. (2011). Invasion Factors Are Coupled to Key Signalling Events Leading to the Establishment of Infection in Apicomplexan Parasites. Cell. Microbiol. 13 (6), 787-796. doi: 10.1111/j.1462-5822.2011.01585.x

Scarpelli, P. H., Tessarin-Almeida, G., Viçoso, K. L., Lima, W. R., Borges-Pereira, L., Meissner, K. A., et al. (2018). Melatonin Activates FIS1, DYN1, and DYN2 Plasmodium Falciparum Related-Genes for Mitochondria Fission: Mitoemerald-GFP as a Tool to Visualize Mitochondria Structure. J. Pineal Res. 66, 1-12. doi: 10.1111/jpi.12484

Scheibel, L. W., Colombani, P. M., Hess, A. D., Aikawa, M., Atkinson, C. T., and Milhous, W. K. (1987). Calcium and Calmodulin Antagonists Inhibit Human Malaria Parasites (Plasmodium Falciparum): Implications for Drug Design. Proc. Natl. Acad. Sci. U. S. A. 84, 7310-7314. doi: 10.1073/pnas.84.20.7310

Shortt, H. E., and Garnham, P. C. (1948). Pre-Erythrocytic Stage of Mammalian Malaria Parasites. Nature 161, 126-127. doi: 10.1038/161126b0

Siden-Kiamos, I., Ecker, A., Nybäck, S., Louis, C., Sinden, R. E., and Billker, O. (2006). Plasmodium Berghei Calcium-Dependent Protein Kinase 3 Is Required for Ookinete Gliding Motility and Mosquito Midgut Invasion. Mol. Microbiol. 60, 1355-1363. doi: 10.1111/j.1365-2958.2006.05189.x

Singh, S., Alam, M. M., Pal-Bhowmick, I., Brzostowski, J. A., and Chitnis, C. E. (2010). Distinct External Signals Trigger Sequential Release of Apical Organelles During Erythrocyte Invasion by Malaria Parasites. PloS Pathog 6 (2), 1-14. doi: 10.1371/journal.ppat.1000746

Singh, S., and Chitnis, C. E. (2012). Signalling Mechanisms Involved in Apical Organelle Discharge During Host Cell Invasion by Apicomplexan Parasites. Microbes Infect. 14, 820-824. doi: 10.1016/j.micinf.2012.05.007

Singh, S., More, K. R., and Chitnis, C. E. (2014). Role of Calcineurin and Actin Dynamics in Regulated Secretion of Microneme Proteins in Plasmodium Falciparum Merozoites During Erythrocyte Invasion. Cell. Microbiol. 16 (1), 50-63. doi: $10.1111 / \mathrm{cmi} .12177$

Steinbach, W. J., Reedy, J. L., Cramer, R. A., Perfect, J. R., and Heitman, J. (2007). Harnessing Calcineurin as a Novel Anti-Infective Agent Against Invasive Fungal Infections. Nat. Rev. Microbiol. 5 (6), 418-430. doi: 10.1038/nrmicro1680

Tanabe, K., Mikkelsen, R. B., and Wallach, D. F. H. (1982). Calcium Transport of Plasmodium Chabaudi-Infected Erythrocytes. J. Cell Biol. 93, 680-684. doi: $10.1083 /$ jcb. 93.3 .680

Tan, M. S. Y., Koussis, K., Withers-Martinez, C., Howell, S. A., Thomas, J. A., Hackett, F., et al. (2021). Autocatalytic Activation of a Malarial Egress Protease is Druggable and Requires a Protein Cofactor. EMBO J. 40, 1-18. doi: $10.15252 / \mathrm{embj} .2020107226$

Tewari, R., Straschil, U., Bateman, A., Böhme, U., Cherevach, I., Gong, P., et al. (2010). The Systematic Functional Analysis of Plasmodium Protein Kinases
Identifies Essential Regulators of Mosquito Transmission. Cell Host Microbe 8, 377-387. doi: 10.1016/j.chom.2010.09.006

Thomas, J. A., Tan, M. S. Y., Bisson, C., Borg, A., Umrekar, T. R., Hackett, F., et al. (2018). A Protease Cascade Regulates Release of the Human Malaria Parasite Plasmodium Falciparum From Host Red Blood Cells. Nat. Microbiol. 3, 447455. doi: 10.1038/s41564-018-0111-0

Tong, J. X., Chandramohanadas, R., and Tan, K. S.-W. (2018). High-Content Screening of the Medicines for Malaria Venture Pathogen Box for Plasmodium Falciparum Digestive Vacuole-. Antimicrob. Agents Chemother. 62, 1-17. doi: 10.1128/AAC.02031-17

Uyemura, S. A., Luo, S., Moreno, S. N. J., and Docampo, R. (2000). Oxidative Phosphorylation, Ca2+ Transport, and Fatty Acid-Induced Uncoupling in Malaria Parasites Mitochondria. J. Biol. Chem. 275, 9709-9715. doi: 10.1074/ jbc.275.13.9709

Vaid, A., and Sharma, P. (2006). PfPKB, a Protein Kinase B-Like Enzyme From Plasmodium Falciparum: II. Identification of Calcium/Calmodulin as Its Upstream Activator and Dissection of a Novel Signaling Pathway. J. Biol. Chem. 281, 27126-27133. doi: 10.1074/jbc.M601914200

Vaid, A., Thomas, D. C., and Sharma, P. (2008). Role of Ca2+/calmodulin-PfPKB Signaling Pathway in Erythrocyte Invasion by Plasmodium Falciparum. J. Biol. Chem. 283, 5589-5597. doi: 10.1074/jbc.M708465200

Vercesi, A. E., Moreno, S. N. J., and Docampo, R. (1994). Ca2+/H+ Exchange in Acidic Vacuoles of Trypanosoma Brucei. Biochem. J. 304, 227-233. doi: $10.1042 /$ bj3040227

Vidadala, R. S. R., Ojo, K. K., Johnson, S. M., Zhang, Z., Leonard, S. E., Mitra, A., et al. (2014). Development of Potent and Selective Plasmodium Falciparum Calcium-Dependent Protein Kinase 4 (PfCDPK4) Inhibitors That Block the Transmission of Malaria to Mosquitoes. Eur. J. Med. Chem. 74, 562-573. doi: 10.1016/j.ejmech.2013.12.048

Wasserman, M., Alarcon, C., and Mendoza, P. M. (1982). Effects of Ca2+ Depletion on the Asexual Cell Cycle of Plasmodium Falciparum. Am. J. Trop. Med. Hyg. 31, 711-717. doi: 10.4269/ajtmh.1982.31.711

Wernimont, A. K., Artz, J. D., Finerty, J. R. P., Lin, Y., Amani, M., Allali-hassani, A., et al. (2010). Structures of Apicomplexan Calcium-Dependent Protein Kinases Reveal Mechanism of Activation by Calcium. Nat. Struct. Mol. Biol. 17, 596-601. doi: 10.1038/nsmb.1795.Structures

Wilkes, J. M., and Doerig, C. (2008). The Protein-Phosphatome of the Human Malaria Parasite Plasmodium Falciparum. BMC Genomics 9 (412), 1-19. doi: 10.1186/1471-2164-9-412

Wilkins, B. J., and Molkentin, J. D. (2004). Calcium-Calcineurin Signaling in the Regulation of Cardiac Hypertrophy. Biochem. Biophys. Res. Commun. 322 (4), 1178-1191. doi: 10.1016/j.bbrc.2004.07.12`1

Yang, C., and Arrizabalaga, G. (2017). The Serine/Threonine Phosphatases of Apicomplexan Parasites. Mol. Microbiol. 106, 1-21. doi: 10.1111/mmi.13715

Conflict of Interest: The authors declare that the research was conducted in the absence of any commercial or financial relationships that could be construed as a potential conflict of interest.

Publisher's Note: All claims expressed in this article are solely those of the authors and do not necessarily represent those of their affiliated organizations, or those of the publisher, the editors and the reviewers. Any product that may be evaluated in this article, or claim that may be made by its manufacturer, is not guaranteed or endorsed by the publisher.

Copyright (c) 2021 de Oliveira, Alborghetti, Carneiro, Bastos, Amino, Grellier and Charneau. This is an open-access article distributed under the terms of the Creative Commons Attribution License (CC BY). The use, distribution or reproduction in other forums is permitted, provided the original author(s) and the copyright owner(s) are credited and that the original publication in this journal is cited, in accordance with accepted academic practice. No use, distribution or reproduction is permitted which does not comply with these terms. 


\section{GLOSSARY}

\begin{tabular}{|c|c|}
\hline IP3R & inositol-1,4,5-triphosphate receptor \\
\hline IP3 & inositol-1,4,5-triphosphate \\
\hline ER & endoplasmic reticulum \\
\hline SOCES & store-operated calcium channels \\
\hline PMCA & plasma membrane $\mathrm{Ca}^{2+}$-ATPase \\
\hline SERCA & sarco(endo)plasmic reticulum $\mathrm{Ca}^{2+}$-ATPase \\
\hline PLC & phospholipase C \\
\hline $\mathrm{PI}(4,5) \mathrm{P}_{2}$ & phosphatidylinositol 4,5-biphosphate \\
\hline RBCs & red blood cells \\
\hline $\mathrm{RBCM}$ & red blood cell membrane \\
\hline PVM & parasitophorous vacuole membrane \\
\hline iRBCs & infected red blood cells \\
\hline uRBCs & uninfected red blood cells \\
\hline EIPA & ethylisopropyl-amiloride \\
\hline PTEX & Plasmodium translocon of exported proteins \\
\hline PV & parasitophorous vacuole \\
\hline cAMP & cyclic-adenosine monophosphate \\
\hline$P f A C \beta$ & P. falciparum adenylyl-cyclase $\beta$ \\
\hline $\mathrm{HCO}_{3}^{-}$ & bicarbonate ion \\
\hline Epac & exchange protein directly activated by CAMP \\
\hline Rap1 & Ras-related protein 1 \\
\hline PfSR25 & G-protein-coupled receptor-like \\
\hline U73122 & inhibitor of PLC \\
\hline 2-APB & 2-aminoethyl diphenylborinate, inhibitor of IP3 signaling \\
\hline PfATP6 & a P. falciparum SERCA-type $\mathrm{Ca}^{2+}$-ATPase \\
\hline Thg & thapsigargin \\
\hline FV & food vacuole \\
\hline PPi & pyrophosphate \\
\hline PolyP & polyphosphate \\
\hline VP1 & vacuolar- $\mathrm{H}^{+}$-pyrophosphatase \\
\hline V-ATPase & vacuolar- $\mathrm{H}^{+}$-ATPase \\
\hline$C Q$ & chloroquine \\
\hline PfCRT & P. falciparum chloroquine resistance transporter \\
\hline FVM & food vacuole membrane \\
\hline TgA1 & T. gondii $\mathrm{Ca}^{2+} / \mathrm{H}^{+}$-ATPase \\
\hline TgVP1 & T. gondii vacuolar-type $\mathrm{H}^{+}$-pyrophosphatase \\
\hline AMDP & amino-methylene-diphosphonate \\
\hline TbPMC1 & T. brucei vacuolar-Ca ${ }^{2+}$-ATPase \\
\hline$P f C H A$ or $P f C A X$ & $\begin{array}{l}\text { P. falciparum } \mathrm{Ca}^{2+} / \mathrm{H}^{+} \text {antiporter or } P \text {. falciparum } \mathrm{Ca}^{2+} / \mathrm{H}^{+} \\
\text {exchanger }\end{array}$ \\
\hline CaBPs & $\mathrm{Ca}^{2+}$ binding proteins \\
\hline EF-hand motif & motif for $\mathrm{Ca}^{2+}$ binding \\
\hline $\mathrm{CaM}$ & calmodulin \\
\hline $\mathrm{CBL}$ & calcineurin B-like family \\
\hline CDPKs & $\mathrm{Ca}^{2+}$-dependent protein kinases family $(1-7)$ \\
\hline PfPKB & P. falciparum protein kinase B \\
\hline PfGAP45 & P. falciparum glideosome-associated protein 45 \\
\hline
\end{tabular}

Continued

\begin{tabular}{|c|c|}
\hline IMC & inner membrane complex \\
\hline PfCENS & P. falciparum centrins (1-4) \\
\hline MTOC & microtubule-organizing center \\
\hline CaMKs & $\mathrm{Ca}^{2+} / \mathrm{CaM}$-dependent kinases \\
\hline PfPK2 & P. falciparum protein kinase 2 \\
\hline PKG & cGMP-dependent protein kinase \\
\hline PKA & cAMP- dependent protein kinase \\
\hline IMC1g & inner membrane complex protein $1 \mathrm{~g}$ \\
\hline ITRAQ & isobaric tag for relative and absolute quantification \\
\hline PfSERA5 & P. falciparum serine repeat antigen 5 \\
\hline HSP90 & heat-shock protein \\
\hline HSPGs & heparan sulphate proteoglycans \\
\hline CSP & circumsporozoite protein \\
\hline STPPs & serine/threonine protein phosphatases \\
\hline $\mathrm{CN}$ & calcineurin \\
\hline CNA & catalytic subunit of the calcineurin \\
\hline CNB & regulatory subunit of the calcineurin \\
\hline AMA1-RON2 & apical membrane antigen-1/rhoptry neck protein 2 \\
\hline PP7 & protein phosphatase 7 \\
\hline $\mathrm{IQ}$ & $\begin{array}{l}\text { the first two amino acids of the calmodulin binding motif: lle } \\
\text { and Gln }\end{array}$ \\
\hline PPP8 & serine/threonine protein phosphatase 8 \\
\hline EBA-175 & 175 kDa erythrocyte binding antigen \\
\hline PfRh1 & P. falciparum reticulocyte binding-like protein 1 \\
\hline PflMC1I & P. falciparum inner membrane complex 11 \\
\hline GAP40 & glideosome-associated protein 40 \\
\hline SOC6 & substrate of CDPK4 6 \\
\hline glyA & glycophorin A \\
\hline CLAG3.1/ & cytoadherence-linked asexual protein gene 3.1 \\
\hline RhopH1 & \\
\hline PfRh2b & P. falciparum reticulocyte binding-like protein $2 \mathrm{~b}$ \\
\hline PbRON11 & P. berghei rhoptry neck protein 11 \\
\hline cGMP & cyclic guanosine monophosphate \\
\hline ICM-1 & important for calcium mobilization-1 protein \\
\hline $\mathrm{CKO}$ & conditional knockout \\
\hline $\mathrm{GC} \alpha$ & guanylyl cyclase alpha \\
\hline PfPDE $\beta$ & P. falciparum phosphodiesterase beta \\
\hline PfMyoA & P. falciparum myosin A \\
\hline CREC family & Calumenin, Reticulocalbin 1 and 3, ERC-55, Cab-45 \\
\hline PfERC & $\begin{array}{l}\text { P. falciparum endoplasmic reticulum-resident calcium-binding } \\
\text { protein }\end{array}$ \\
\hline CPA & cyclopiazonic acid \\
\hline SUB1 & subtilisin-like protease \\
\hline PMX & plasmepsin X \\
\hline MSP1 & merozoite surface protein 1 \\
\hline EEF & exo-erythrocytic form \\
\hline $\mathrm{NF}-\kappa \mathrm{B}$ & nuclear factor $\kappa \mathrm{B}$ \\
\hline CXCR4 & C-X-C chemokine receptor type 4 \\
\hline BiolD & proximity-dependent biotin identification \\
\hline APEX-2 & ascorbate peroxidase-2 \\
\hline
\end{tabular}

